\title{
Large-Scale Dimensional Metrology (LSDM): from Tapes and Theodolites to Multi-Sensor Systems
}

\author{
Fiorenzo Franceschini',", Maurizio Galetto', Domenico Maisano', and Luca Mastrogiacomo' \\ 1 Politecnico di Torino, DIGEP (Department of Management and Production Engineering), Corso Duca degli Abruzzi 24, 10129, Torino, Italy \\ \# Corresponding Author / E-mail: fiorenzo.franceschini@polito.it, TEL: +39-011-0907225, FAX: +39-011-0907299
}

KEYWORDS: Coordinate measurement systems, Large-scale dimensional metrology, Large-volume dimensional metrology, Multi-sensor systems

\begin{abstract}
Last decades witness an increasing interest in Large-Scale/Large-Volume Dimensional Metrology (LSDM). Many fields of application, ranging from construction to shipbuilding and aerospace, have shown more and more accurate and versatile systems for geometric control and tolerancing. Especially in the last ten years, optical technology has registered a fundamental step forward both in terms of metrological performances, versatility and convenience of use. This is further demonstrated by the current large diffusion of laser tracker and photogrammetric systems. The growth is also complemented by the development of new standards, even though a comprehensive body specific for LSDM is still lacking. The twofold aim of the present survey is to present a bibliographical and bibliometric analysis of the field and to propose a scheme of classification of the main current approaches. As an output of this paper, a "LSDM Multi-perspective Model" is introduced, according to which dominant technologies and restrictions are analyzed with the aim of individuating current lacks and defining the roadmap for future development of new instruments and systems.
\end{abstract}

\section{Introduction and Literature Review}

In the field of dimensional metrology a role of particular relevance is played by the so called Large-Scale/Large-Volume Dimensional Metrology (LSDM), which, reminding Puttock's definition (1978), ${ }^{1}$ is commonly defined as that branch of metrology dealing with "objects with linear dimensions ranging from tents to hundreds of meters".

Last decades has shown a great deal of applications of LSDM, involving different arenas of technology, ranging from civil and industrial architecture to aerospace engineering. ${ }^{1-9}$ Typical applications refer to the measurement of large machines and structures, such as for example in the aeronautic and shipbuilder industry, but also in the field of topographical and architectural surveying. ${ }^{10-24} \mathrm{~A}$ branch of application, which is often neglected by the scientific literature when referring to LSDM, concerns the tracking of objects in movement in large spaces, such as for examples warehouses or industrial plants, or even over the territory. ${ }^{25-27}$ Systems like GPS (Global Positioning System) are rarely considered in the field LSDM although they are actually employed in many kind of measurement of large-scale structures specially in shipyard for shipbuilding industry and industrial ports, as well as for topographic and architectonic surveying. ${ }^{15,28-32}$ Currently, we can say that there is an overlapping between the areas of traditional tracking systems, for example GPS, and systems commonly used for LSDM application. In fact, just as GPS can be used for dimensional measurement, many typical LSDM systems are used for indoor tracking. ${ }^{25-27,33}$

Referring to industrial engineering, it must be highlighted that the most typical applications of LSDM systems concern the assembly/ disassembly phase and/or in-situ dimensional tolerancing of large volume objects. Many examples reported in the scientific literature confirm this tendency. ${ }^{18-21,34-41}$ Other typical applications are for reverse engineering and tracking of automated arms or moving robots. ${ }^{25-27,42}$

The current evolution towards intelligent and automated systems is more and more making possible the complete integration of them in the modern automated production systems. In particular, the last thirty/ forty years have seen the changeover from the so called "classical method", such as for example tapes and wires, to modern optical systems, which allow fast and precise acquisition even in particular conditions of length and distance from the measured object. ${ }^{1-9}$ The current trend is towards multi-sensor systems, able to integrate together devices of different nature and distributed inside the working volume. ${ }^{9,43-50}$ Overall, the main objective of LSDM is to obtain measurement systems easy to install, possibly in the same place in 
which the object is constructed or utilized, characterized by a short acquisition time, accurate, able to perform contactless measurement also at a considerable distance from the measured object, in different working conditions and as cheaper as possible. Some commercial or prototypal systems have been realized with these objectives, at the current state of the art it is worth citing in particular photogrammetric systems and laser radars, which, apart from the economical aspect, are heading towards this direction with interesting results. ${ }^{6-8,51-65}$

The industrial interest towards LSDM systems is also attested by the considerable number of patents registered starting from the Eighties, especially referring to laser interferometry, and in particular to lasertrackers and laser-radars, and to photogrammetry. ${ }^{8,66,67}$ The scientific literature shows a great interest about LSDM systems and their applications, but with different aims, varying from the simple description of innovative optical, ultrasound, hybrid and traditional systems to the procedure for their characterization and for uncertainty assessment. ${ }^{1-9}$

The aim of the survey presented in this paper is to give an inside view of the field, starting from a comprehensive review and analysis of the current literature and body of patents, and then focusing on the classification of the most studied and diffused systems. The goal is to highlight the dominant and emerging technologies in order to provide a snapshot of the state of the art and give a vision of the future trends.

One of the main outputs of the research is the introduction of a "LSDM Multi-perspective Model" able to individuate current lacks and defining the roadmap for future development of new instruments and systems, as well as providing an operative tool for making comparisons between current technologies and individuating their advantages and disadvantages.

The work is organized on a set of taxonomies aimed at classifying the existing and the possible future systems from different points of view ranging from the physical working principles to the measured object characteristics and to the use restrictions.

The remaining of this paper is organized as follows: Section 2 presents the state of the art and the evolution over the years of LSDM. Section 3 briefly describes the approach inspiring the here proposed taxonomy and discusses the results obtained from the analysis of the current scientific literature and patents. Section 4 focuses on the perspectives and the criteria of classification. It also provides some examples of the most diffused LSDM technologies. Section 5 sums up the considerations arisen from the research and tries to give an outlook of the future trends

\section{State of the Art and LSDM Evolution}

\subsection{The so called "classical instruments"}

In the early Sixties, LSDM was referring essentially to length and angle and the techniques involved were originating from geographical surveying instruments and methods.

Until then, the most employed instruments were tapes, wires, sticks, optical alignment systems and theodolites, but just in the second half of the Nineteenth century the first instruments based on laser interferometry started to see their massive employment, first for dealing with alignment issues, then for range and length measurements. ${ }^{1}$

\subsection{The rise of a new generation of measuring systems: the laser} trackers

A significant turning point occurred at the beginning of 1980s when Lau and Hocken proposed the laser tracker. ${ }^{8,68}$ This gave rise to a new generation of measuring systems which is still extensively used for large-scale industrial and scientific metrology. Current laser trackers, based on the combined use of built-in Absolute Distance Meters (ADM) and Relative-Displacement-Measuring Interferometer (IFM), differentiate from the original ones, which permitted only the measurement of a displacement from a datum position since they were just equipped by an IFM. This makes more practical and easier the use of laser trackers because the ADM permits the resetting of the measuring system without having to return the retro-reflector to the datum position. The introduction of the most recent versions of laser trackers, only based on ADM technology, has improved significantly the acquisition speed, giving almost real-time distance measurement performance, even though assuring high levels of accuracy (typically $10 \pm 0.4 \mu \mathrm{m} / \mathrm{m}$ ). ${ }^{69-72}$ A further improvement of laser trackers has been obtained in the last years with the introduction of specific $6 \mathrm{DOF}$ probes able to return the exact position of the touched point or (depending on the characteristics of the specific probe) a local scansion of the portion of the measured surface. $^{69,70}$

\subsection{Traditional CMMs}

Traditional gantry and horizontal-arm CMMs are still largely employed systems for LSDM applications. ${ }^{72-75}$ Nevertheless, even if they assure a very high level of accuracy and the advantage of providing the coordinate measurement of (potentially) all the sides of the measured object, their use is strongly limited by two restrictions, which often represent inevitable exclusion elements for their employment in many operative contexts:

(i) the first one is the impossibility of moving the CMM to the measurement object, hence no in-situ measurement can be performed and the measured object must always be transported to the CMM laboratory;

(ii) the second one is related to its monolithic structure in which the probe is always joined to the main frame through a specific arm, this prevents the free movement of the probe inside the measurement volume without colliding with the measured object.

\subsection{Laser radars}

Coherent Laser Radars (CLR) are the immediate alternative to laser trackers, they allow fast and accurate measurement of surfaces without needing collaborative markers. ${ }^{70,72}$ CLR technology is based on the principle of Frequency-Moduled Continuous-Wave (FMCW), which permits to obtain absolute distance measurements without the use of specific cooperative markers, analysing the coherent interference of an opportunely shaped InfraRed (IR) signal and the corresponding reflected signal from the target surface. ${ }^{51,62}$ Although this technology does not ensure the same level of accuracy of laser trackers, it presents remarkable advantages in terms of data density, even over large surfaces, and the ability to measure non-cooperative markers and featureless surfaces. 


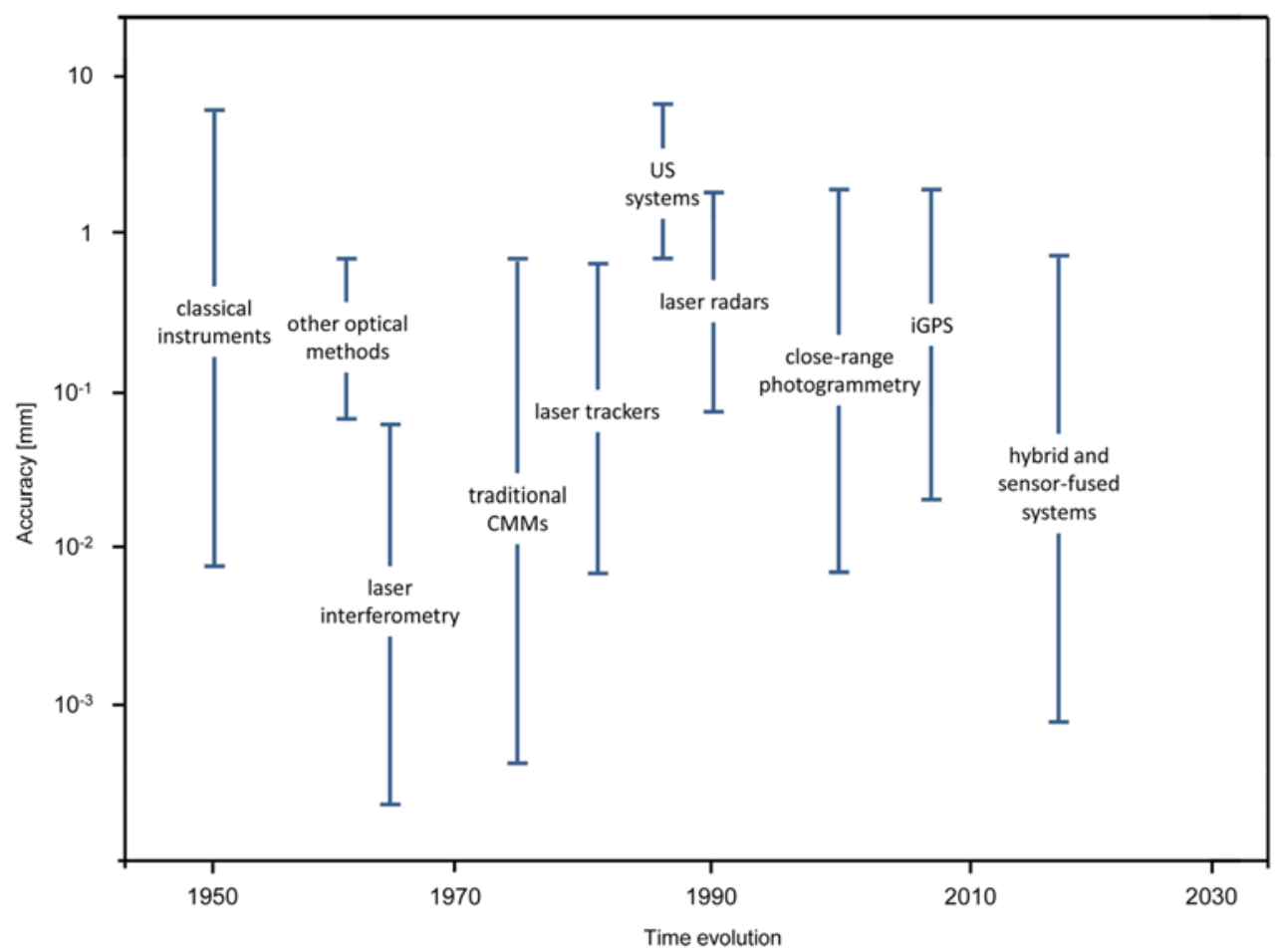

Fig. 1 Evolution of the main families of LSDM systems and relating accuracy over time

\section{5 iGPS and distributed systems}

One of the most interesting systems recently introduced in the field of LSDM is the Indoor-GPS (iGPS), which is a successful example of a category of instruments identified as Rotary-Laser Automatic Theodolites (R-LAT). ${ }^{33,72,76-79}$ The system components of iGPS are a network of transmitters, a control centre and a number of wireless probe sensors. Transmitters use laser and infrared light to determine the relative angles from the transmitters to the probe-sensors. These latters have photodiodes inside their modules that can sense the transmitted laser and infrared light signals. Based on the known location of the transmitters, which is normally obtained in an initial network calibration phase, the position of the sensors can be subsequently calculated. ${ }^{72,76}$ In short, from the operational point of view, iGPS shares similarities with traditional theodolite surveying and GPS navigation systems.

\subsection{The explosion of digital photogrammetry}

The great revolution of the beginning of 2000s is represented by the close-range photogrammetry. Actually, from the formal point of view, photogrammetry founds its origins at the beginning of the past century specially in surveying applications, but, with the introduction of digital cameras, it revealed its great potentiality. The fundamental principle used by photogrammetry is triangulation. By taking photographs or video images from at least two different locations, so-called "lines of sight" can be developed from each camera to points on the object. These lines of sight (sometimes called rays owing to their optical nature) are mathematically intersected to produce the 3-dimensional coordinates of the points of interest. ${ }^{10,57,59,60,63-65}$ It is easy to understand that when photogrammetry was based on traditional photograph, the elaboration was difficult and required quite a bit of time. With the introduction of digital cameras, and the consequent transformation in digital photogrammetry, measurement time reduced enormously, allowing real time tracking, and the level of accuracy became comparable to other LSDM systems. The great advantage of digital photogrammetry is to provide a non-contact method for determining surface shape, position and orientation that is particularly suited to the monitoring of movement and change over time. ${ }^{59}$

\subsection{Other optical methods}

Laser line scanners, structured light systems and shading methods complete the technological map of the so called optical methods, which base their working principles on some sort of structured light. They offer great advantages in terms of data density and fast data collection speed for that reason they are largely employed for reverse engineering application. However they do not ensure the same level of accuracy of other systems such as laser trackers, laser radars, iGPS, etc. Furthermore, their application is restricted to smaller volumes and surface with linear dimensions of few meters. ${ }^{8,52,53,56}$

\subsection{UltraSound systems}

A different family of systems is that composed by instruments basing their working principle on UltraSound (US) transmission. Though these systems do not guarantee the same level of accuracy of optical and contact ones, they have gathered a good interest from the scientific and industrial point of view, especially for their low costs of acquisition and implementation. ${ }^{9,80-82}$

\subsection{Hybrid systems}

A separate subject concerns the so called "hybrid systems", that is all systems obtained by integrating two or more different technologies. ${ }^{8}$ Typical examples of this kind of systems are total stations, essentially 
Table 1 Description of the five perspectives used for the classification and analysis of LSDM systems

\begin{tabular}{ll}
\hline \multicolumn{1}{c}{ Analysis perspectives } & \multicolumn{1}{c}{ Description } \\
\hline 1 - System organization & $\begin{array}{l}\text { This perspective is related to the physical principles on which the system is based. It comprises the hardware } \\
\text { organization and the way the system is interfaced to the measured object. }\end{array}$ \\
\hline 2 - Performance & $\begin{array}{l}\text { This dimension includes the main metrological and operational characteristics of the system ranging from accuracy } \\
\text { to scale width and measuring time. }\end{array}$ \\
\hline 3 - Working part restrictions & $\begin{array}{l}\text { Analysis of all the main elements characterizing the measured object, which may affect the procedure of } \\
\text { measurement and related results. }\end{array}$ \\
\hline 5 - Environmental restrictions & $\begin{array}{l}\text { Analysis of conditions related to the working environment, which may affect the procedure of measurement and } \\
\text { related results. }\end{array}$ \\
\hline 5 - Use conditions & $\begin{array}{l}\text { Analysis of the main elements related to the use of a measurement system: costs, field of application, ergonomics, } \\
\text { etc.. }\end{array}$ \\
\hline
\end{tabular}

composed by theodolites with added distance measurement capability. ${ }^{83}$ The advantage of hybrid systems is that they can incorporate all the advantages of different instruments they integrate. Typical integration refer to laser scanning and close-range photogrammetry or structured light, furthermore great advantages can be reached by equipping automatic systems with video imaging devices. Considering all the possible combinations, a multitude of different types of hybrid opticalbased measuring systems can be imagined, with their advantages and drawbacks. An interesting review of traditional and less known optical techniques is provided by Chen et al. (2000). ${ }^{53,80,84-86}$

\subsection{Looking at the future}

Looking at the new generations of systems, the trend of LSDM seems oriented towards distributed systems, i.e., systems composed by different typology of devices, (all together) cooperating in order to pursue the common objective of giving a measurement result as much as accurate and precise as possible, reliable, repeatable and stable over time. This is the case, for example, of laser tracker multilateration systems, and laser trackers and photogrammetry integrated systems. ${ }^{44,86-}$ ${ }^{89}$ Recent papers about sensor fusion and data fusion techniques present an interesting assortment of this kind of application. ${ }^{43,46-48,50,80}$

A rough scheme about the temporal evolution of the main families of LSDM systems and relating accuracy is reported in Fig. 1.

\section{Analysis Criteria and Methodology Description}

Looking at this large variety of LSDM systems, a rational approach to classify and analyze them from the technological and operational point of view is mandatory. The paradigm here presented, based on an in-depth analysis of the recent scientific literature and on the patents registered in the last thirty years, has the aim of rationalizing and classifying the large mass of LSDM instruments. A series of taxonomies, which analyses the various aspects of a LSDM measurement system, is proposed. A set of five "analysis perspectives" has been identified (see Table 1). These perspectives rise from the technological and operational dimensions proposed in the scientific literature for analyzing and comparing LSDM systems. ${ }^{90}$

Each perspective is subsequently split in further criteria and/or subcriteria of analysis (see Table 2).

The five perspectives allow to analyze the different LSDM measurement systems both from the technological and the operational point of view. Similar classifications have been widely proposed in
Table 2 Criteria of classification and analysis of LSDM systems

\begin{tabular}{|c|c|}
\hline $\begin{array}{c}\text { Analysis } \\
\text { perspectives }\end{array}$ & Criteria \\
\hline \multirow{4}{*}{$\begin{array}{l}1 \text { - System } \\
\quad \text { organization }\end{array}$} & 1.1 - Dominant technology \\
\hline & 1.2 - Hardware organization \\
\hline & 1.3 - Interaction with the measured object \\
\hline & 1.4 - Measurement principle \\
\hline \multirow{3}{*}{2 - Performance } & $\begin{array}{l}2.1 \text { - Total accuracy (which includes precision } \\
\text { and trueness) }\end{array}$ \\
\hline & $\begin{array}{l}2.2 \text { - Scale size (longest length in the volumetric } \\
\text { coverage) }\end{array}$ \\
\hline & $\begin{array}{l}2.3 \text { - Measurement time (including positioning } \\
\text { and setup) }\end{array}$ \\
\hline \multirow{3}{*}{$\begin{array}{l}3 \text { - Working part } \\
\text { restrictions }\end{array}$} & 3.1 - Material \\
\hline & 3.2 - Surface quality \\
\hline & 3.3 - Accessibility (location of measured points) \\
\hline \multirow{5}{*}{$\begin{array}{l}4 \text { - Environmental } \\
\text { restrictions }\end{array}$} & 4.1 - Working temperature \\
\hline & 4.2 - Working humidity \\
\hline & 4.3 - Working pressure \\
\hline & 4.4 - Location \\
\hline & 4.5 - Noise factors \\
\hline \multirow{8}{*}{5 - Use conditions } & $5.1-$ Cost \\
\hline & 5.2 - Supported software \\
\hline & 5.3 - Standards \\
\hline & 5.4 - Application fields \\
\hline & 5.5 - System diffusion \\
\hline & 5.6 - Technological obsolescence \\
\hline & 5.7 - Technological complexity \\
\hline & 5.8 - Ergonomics (easiness of use) \\
\hline
\end{tabular}

literature with the aim of providing an overview of the most important criteria for the selection of measurement processes and for the choice of the appropriate instrument for a given task. ${ }^{7,18,34,35,90}$

The peculiarity of the present work is that it provides a set of taxonomies which give a synoptic inside view of the state of the art and allow to identify the technological areas that still need to be covered in order to trace out the possible evolutions for the future. The mainstream of this approach is based on a detailed analysis of the working principles of the current measurement systems. It starts with a deep bibliometric analysis of the whole recent literature and a patent reviews related to LSDM in order to give an overall view of the current technologies employed in this field and highlight the zones of major interest.

The analysis is then extended to other issues such as performances, working part and environment restrictions, up to the questions related 

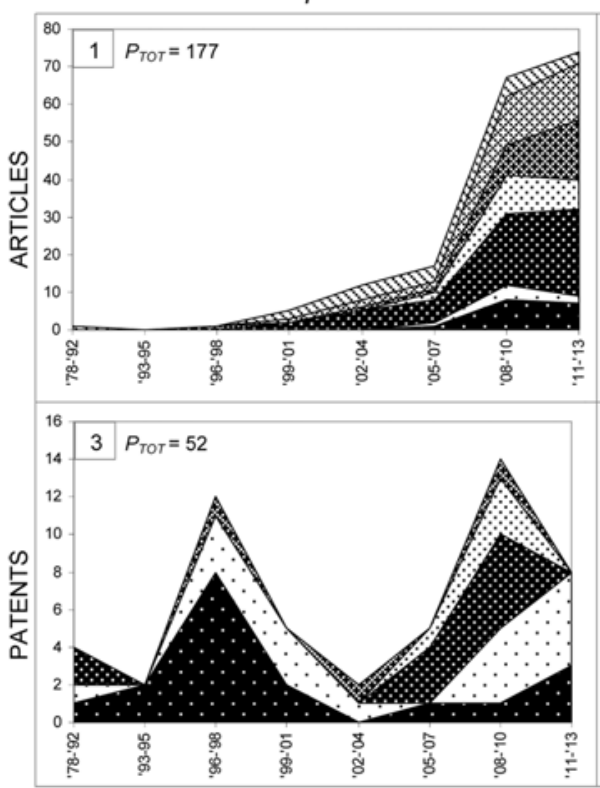

C
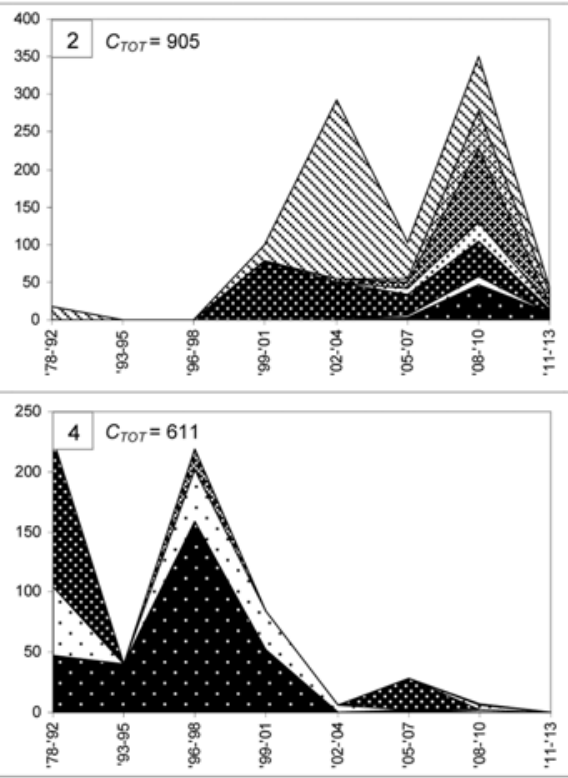

Typology of topic:

A - Description of the measuring system

B - New hardware component(s)

C - New application/working procedure ๑ - Development of system set-up/calibratior G E - Optimization of measurement operations F - Performance analysis

Fig. 2 Temporal distribution of the number of documents (P) and the corresponding citations (C) on the basis of the typology-of-output classification, Charts are constructed both for articles (charts (1) and (2)) and patents (charts (3) and (4)) ${ }^{67}$

Table 3 Classification of documents and their citations, according to their main topic ${ }^{67}$

\begin{tabular}{cl}
\hline $\begin{array}{c}\text { Typology of output } \\
\text { measuring system }\end{array}$ & $\begin{array}{l}\text { Detailed description of a new LSDM system, its technical features, functionality, measurement procedure and } \\
\text { (dis)advantages with respect to other systems. }\end{array}$ \\
\hline $\begin{array}{c}\text { B - New hardware } \\
\text { component(s) }\end{array}$ & $\begin{array}{l}\text { Development and characterization of new hardware components, which replace or complement those of an existing } \\
\text { measuring system, improving its functionality and performance. }\end{array}$ \\
\hline $\begin{array}{c}\text { C - New application/ } \\
\text { working procedure }\end{array}$ & $\begin{array}{l}\text { Description of novel measurement procedures or applications, aimed at expanding and improving the functionality } \\
\text { and/or performance of an existing measuring system. These procedures/applications generally require additional } \\
\text { external hardware equipment. }\end{array}$ \\
\hline $\begin{array}{c}\text { D - Development of system } \\
\text { set-up/calibration }\end{array}$ & $\begin{array}{l}\text { Illustration of a new procedure/algorithm aimed at enhancing the system set-up/calibration stage of an existing } \\
\text { measuring system. }\end{array}$ \\
\hline $\begin{array}{c}\text { E - Optimization of } \\
\text { measurement operations }\end{array}$ & $\begin{array}{l}\text { Improvement of the efficiency/effectiveness of measurement operations and data management. This optimization is } \\
\text { typically software-based and does not imply any change in the measuring system's hardware or the introduction of } \\
\text { external hardware. }\end{array}$ \\
\hline F - Performance analysis & $\begin{array}{l}\text { Analysis of the performance of an existent measuring system (e.g., evaluation of metrological characteristics, such as } \\
\text { repeatability, accuracy, measurement uncertainty, sampling rate, etc.), based on empirical data or simulations. It may } \\
\text { include performance verification according to standards and/or comparison with other measuring systems. }\end{array}$ \\
\hline G - Literature review & \begin{tabular}{l} 
Literature review of the LSDM measuring systems or those based on a specific technology. \\
\hline
\end{tabular}
\end{tabular}

to the system employment. For each category the existing systems are described and potential elements of innovation are highlighted.

As anticipated, the starting point of this survey is the analysis of the scientific literature in the field of LSDM and the patents registered in the last thirty years. An in-depth study about the dualism between articles and patents in LSDM is reported in Franceschini et al. (2014). ${ }^{67}$

Literature analysis has been conducted basing on Scopus database, which ensure a large level of coverage and accuracy in the field of Engineering Science. ${ }^{91-93}$ A partial limitation of Scopus is that it does not index books or book chapters but only articles from leading journals and conference proceedings, which, however, contain the vast majority of the relevant LSDM publications.

A large number of data referring to the number of both published articles and citations have been collected and analyzed. ${ }^{94-97}$

Questel-Orbit has been the reference database for patents, which integrates patent statistics from more than 95 national and international patent authorities. $^{66}$

For both articles and patents, the analysis has been conducted as a first step through an automatic alphanumeric search on specific keywords in the field of LSDM and then manually refined by examining title, abstract and the content of each document.

This procedure for data collection, although being structured and repeatable, has the main limitation of being not free from the risk of omitting a portion of LSDM documents. This risk is certainly present for the literature analysis due to the restrictions of Scopus database, but is even larger for patents, since their language is sometimes captious and can complicate the searching by keywords. ${ }^{98,99}$ Nevertheless the obtained results provide an interesting framework about the evolution of LSDM systems over the years and an attractive prospect of the future trends. 
The survey considered 177 articles (not all of them reported in the References Section of this paper) and 52 patents.

A first rough consideration is that almost all patents deal with new measurement systems, hardware components and working procedures, while for the articles - apart from literature reviews - the main contributions concern working procedures, performance analysis, development of the system set-up/calibration stage, and optimization of measurement operations, for existing measuring systems. Furthermore articles and citations are quite evenly distributed among all the principal technologies, with special interest on Laser-interferometry/ADM, Photogrammetry and Theodolite/RLAT. On the contrary, the number of patents is predominant for Laser-interferometry/ADM, especially concerning laser-trackers. On the other hand, the first position in terms of cited patents is held by Photogrammetry, which is relatively more cited than the other technologies. This is symptomatic of the large industrial interest for this technology, even in contexts outside of LSDM (e.g., videogames and home-entertainment).

Observing the temporal collocation, a substantial misalignment can be observed between articles and patents: a significant portion of patents were issued in the last fifteen years of 20th century, while most of the articles were issued after 2004. Before 1996 the number of articles was very exiguous with a gradual rise until 2008. This year signs a sort of explosion in terms of papers productivity. Apparently, it seems that articles have followed the evolution of patents, probably after the new (patented) technologies became available on the market.

The four diagrams in Fig. 2 depict the temporal collocation of documents and their citations, according to a classification based on their main topic (detailed in Table 3). Time classes include three-years; the only exception is represented by the broader first class (i.e., from 1978 to 1992), because of the relatively low number of documents issued in this period.

\section{LSDM System Taxonomies}

In the following Sections, the five perspectives of analysis of LSDM systems are described in detail and applied to the existing technologies.

\subsection{System organization}

System organization is the basic perspective that allows to classify all the systems from the structure point of view. It also enables the identification of dominant technologies and the ways of implementation.

According to this perspective (see Table 2), four specific criteria of analysis are identified: Dominant technology, Hardware organization, Interaction with the measured object and Measurement principle.

\subsubsection{Dominant technology}

This criterion includes all the main technologies of the vast family of LSDM systems. It permits a univocal and well defined taxonomy of all the existing systems, leaving space for hypothesizing possible evolutions for the future. Dominant technology can be seen as the basic criterion of classification. Fig. 3 shows all the taxonomy categories associated to this criterion.

For each category the most known, diffused and/or innovative systems are reported as examples. For the sake of simplicity, among all the existing systems mentioned in Section 2, only a reduced set of them will be used as examples for the explanation of the different criteria used in the five perspectives of analysis.

\subsubsection{Hardware organization}

LSDM instruments can be classified according to the way the components of the system are organized. Two categories can be defined: ${ }^{9} 100$

Centralized systems: a centralized system is essentially a stand-alone unit which can work independently to provide the measurement of a spatial coordinate on the object surface, e.g., a laser tracker. In some cases, a number of centralized systems can be used simultaneously with the aim of improving measurement accuracy.

Distributed systems: a distributed system consists in a series of measuring stations that work cooperatively to collect information for determining point coordinates. In general, the individual stations cannot measure coordinates separately. Individual stations may be identical devices, or alternatively different kinds of devices (US devices, IR devices, cameras, etc.), distributed in the measurement volume.

\subsubsection{Interaction with the measured object}

The way the system is interfaced to the measured object is a fundamental element for its classification. Also in this case, two main categories can be defined: ${ }^{9}$

Contact systems: a contact measuring system is a metrological system which can provide the coordinate of the object to be measured simply by touching it with a probe. The probe of the metrological system can be moved either manually or by mechanical arms or can be attached to the object as a target to be followed by the system.

Non-contact systems: these systems can evaluate dimensional features of the object to be measured without the need for a probe to touch the object. They are mainly based on optical or US technologies.

Table 4 presents the major LSDM systems classified according to the criteria Hardware organization and Interaction with the measured object.

\subsubsection{Measurement principle}

The last criterion, proposed from point of view of the working principles, identifies the basic measure(s) used for output result reconstruction. From this point of view, the following categories can be identified:

Measuring systems using multiple angles (triangulation): these systems evaluate the position of a point in the measurement space using only angular information from two or more reference points. This working principle relies on the very well-known triangulation algorithms. Triangulation uses the known locations of two or more reference points, and the relative angles between the point to be localized and each reference point. In this case the unknown position of the point can be found by solving a linear system. ${ }^{9}$ Typical examples are camera-based triangulation systems, iGPS, digital photogrammetry, MScMS-II, HiBall.

Measuring systems using multiple lengths (trilateration): Trilateration uses the known locations of three or more reference points, and the measured distance between the point to be localized and each reference point. The unknown coordinates can be found by solving a nonlinear optimization problem. This approach is very similar to GPS (Global 
DOMINANT MEASUREMENT PHYSICAL

TECHNOLOGY

PRINCIPLE

PRINCIPLE

SDM systems

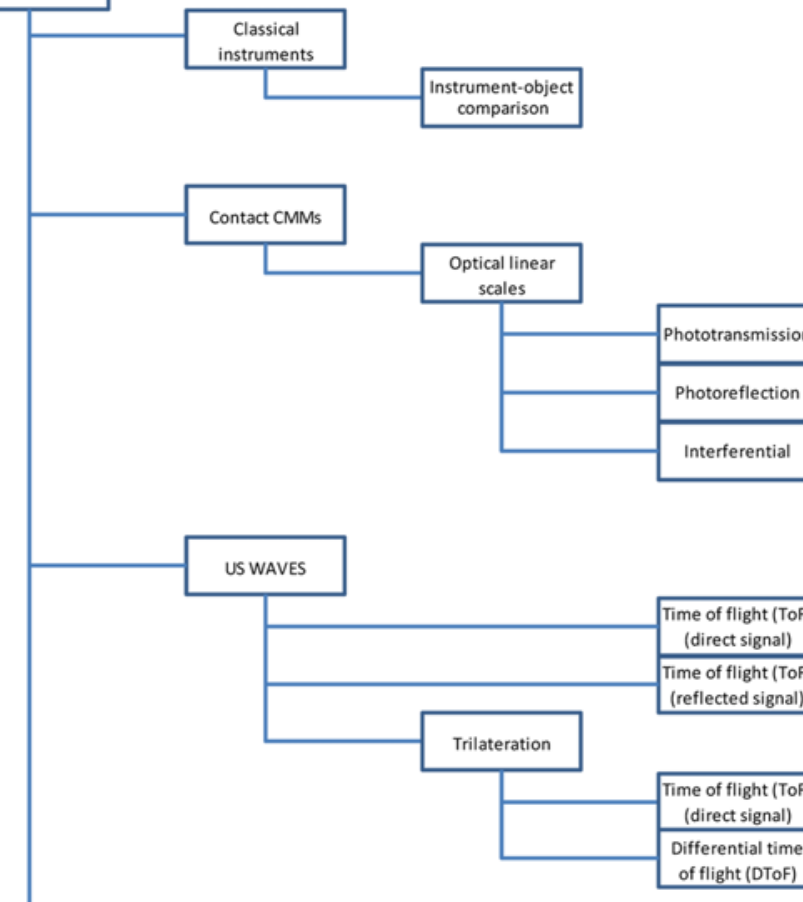

Light/IR waves

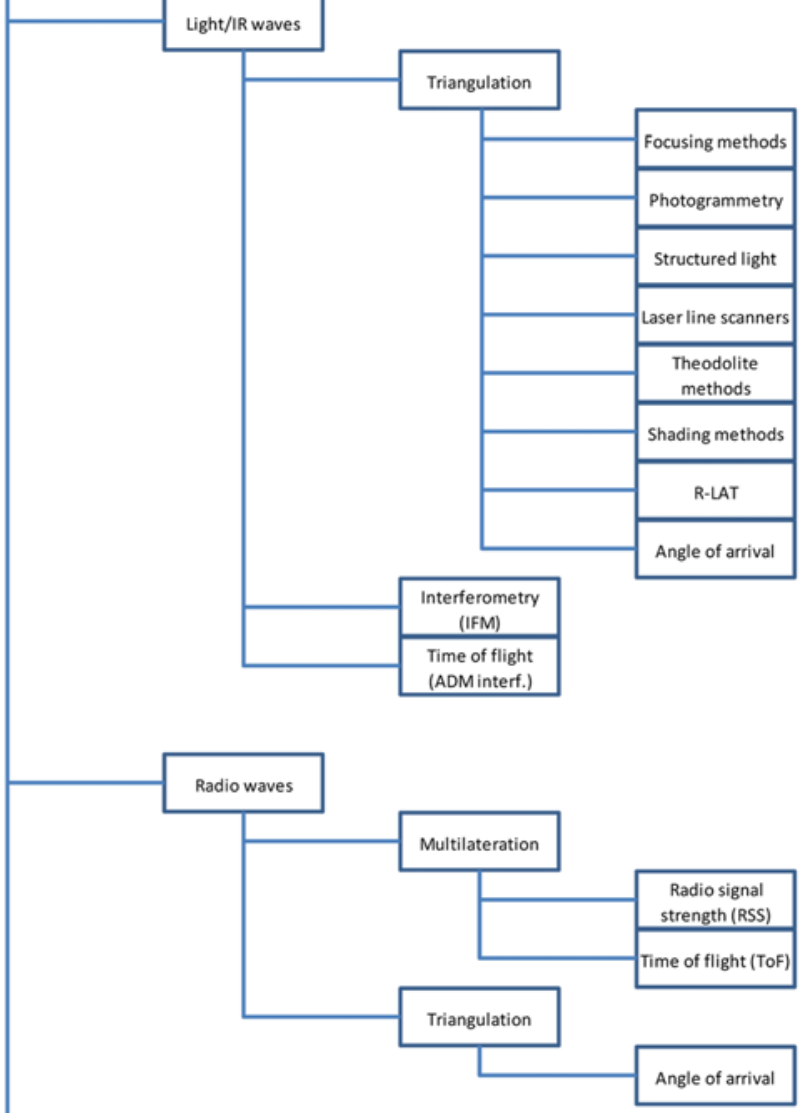

Hybrid systems
MAIN LSDM SYSTEMS

Tapes, wires and sticks

Gantry or horizontal-harm CMMs

Gantry or horizontal-harm CMMs

Gantry or horizontal-harm CMMs

Ultrasonic distance measuring systems

Ultrasonic distance meter

ZEBRIS CMS-HS

Crickets, ALO, MSCMS-I

Vision Measuring Machines (VMM)

Metronor, AICON, Vicon, MSCMS-II, etc.

Konica Minolta, etc.

Konica Minolta, etc.

Leica Geosystems, etc.

Konica Minolta, etc.

iGPS

HiBall

Laser trackers

Laser trackers, laser radars

Mobility systems and research prototypes

GPS

Research protoypes

Fig. 3 Deployment of criterion Dominant technology for LSDM system classification 
Table 4 Classification of major LSDM systems according to the criteria Hardware organization and Interaction with the measured object ${ }^{9}$

\begin{tabular}{ccc}
\hline & Contact & Non-contact \\
\hline Centralized & CMM, laser tracker, total station & $\begin{array}{c}\text { Theodolite, laser radar, tacheometer, } \\
\text { optical probe CMM, camera based triangulation }\end{array}$ \\
\hline Distributed & $\begin{array}{c}\text { iGPS, HiBall, MScMS-I, MScMS-II, contact systems } \\
\text { with multilateration technique }\end{array}$ & $\begin{array}{c}\text { Photogrammetry, non-contact systems } \\
\text { with multilateration technique }\end{array}$ \\
\hline
\end{tabular}

Table 5 Metrological performance indicators according to the International Vocabulary of Metrology (VIM) ${ }^{102}$

\begin{tabular}{|c|c|}
\hline $\begin{array}{c}\text { Metrological } \\
\text { performance indicators }\end{array}$ & Definition \\
\hline Accuracy & closeness of agreement between a measured quantity value and a true quantity value of a measurand. \\
\hline Trueness & $\begin{array}{l}\text { closeness of agreement between the average of an infinite number of replicate measured quantity values and a reference } \\
\text { quantity value. }\end{array}$ \\
\hline Uncertainty & $\begin{array}{l}\text { non-negative parameter characterizing the dispersion of the quantity values being attributed to a measurand, based on } \\
\text { the information used. }\end{array}$ \\
\hline Precision & $\begin{array}{l}\text { closeness of agreement between indications or measured quantity values obtained by replicate measurements on the } \\
\text { same or similar objects under specified conditions. }\end{array}$ \\
\hline Repeatability & measurement precision under a set of repeatability conditions of measurement. \\
\hline Repeatability condition & $\begin{array}{l}\text { condition of measurement, out of a set of conditions that includes the same measurement procedure, same operators, } \\
\text { same measuring system, same operating conditions and same location, and replicate measurements on the same or } \\
\text { similar objects over a short period of time. }\end{array}$ \\
\hline Reproducibility & measurement precision under reproducibility conditions of measurement. \\
\hline Reproducibility condition & $\begin{array}{l}\text { condition of measurement, out of a set of conditions that includes different locations, operators, measuring systems, and } \\
\text { replicate measurements on the same or similar objects. }\end{array}$ \\
\hline Stability & property of a measuring instrument, whereby its metrological properties remain constant in time. \\
\hline Resolution & smallest change in a quantity being measured that causes a perceptible change in the corresponding indication. \\
\hline
\end{tabular}

Positioning System) localisation principle. ${ }^{101}$ Systems based on this working principle are multiple laser interferometers, multiple ADM systems, MScMS-I.

Measuring systems using two angles and one length: Most of the Large-Scale measuring systems rely on the determination of one length and two angles. These systems are also called Spherical Coordinate Measurement Systems because the initial coordinates of a point are evaluated in a spherical coordinate system. Generally, the angles are measured by means of angular encoders, whilst the range measurement can be performed using either IFM or ADM technology. The spherical coordinates are then easily transformed in Cartesian coordinates by a central processing unit that is able to derive the object features from the measured points in the 3D space. Examples of these systems are laser trackers, laser radars and total stations.

\subsection{Performance}

The second perspective considered is that of Performance, which considers LSDM major metrological and operational features.

According to this perspective (see Table 2), three criteria of analysis are identified: Total accuracy (which includes precision and trueness), Scale size (longest length in the volumetric coverage) and Measurement time (including positioning and setup).

\subsubsection{Total accuracy}

This criterion, associated with the second one (Scale size) is of basic importance for defining the level of performance of a LSDM system. Usually these two criteria fall in conflict, due to the intrinsic nature of the dimensional measuring instruments for which, enlarging the extension of the measurand, the related accuracy tends to increase.

The metrological performance of a measuring system is usually tested through the use of specific indicators, generally prescribed by international standards (see Table 5).

Every measuring system can be characterized by evaluating these parameters. In general, when dealing with coordinate measurement systems, performance evaluation refers to the assessment of accuracy, repeatability and reproducibility of the measurement performed in a well-defined point (or portion of volume) in the whole measurement domain of the system. These three performance indicators are enough to indicate locally the quality of a measurement. Furthermore, uncertainty estimation refers to the evaluation of the dispersion associated with measured data and related measuring procedure. This gives an overall indication of the behaviour of the system in the whole space of measurement when a specific measuring procedure is applied.

\subsubsection{Scale size}

Scale size is the criterion that makes the difference between traditional dimensional metrology instruments and LSDM ones. The primary purpose of LSDM is the three-dimensional measurement of large-sized objects. The applications for measurement and control of mechanical structures and machines require very high levels of accuracy. In general, LSDM accuracy refers to objects ranging from 10 to $1000 \mathrm{~m}$ in size, with accuracies around $0.1 \mathrm{~mm}$ at the smaller end and $10 \mathrm{~cm}$ at the larger end (for large structures in space and construction industries). ${ }^{21-23,41,103-108}$ Fig. 4 shows the relationship between size of measured object and related measurement accuracy for the major LSDM technologies as typically presented in the scientific literature.

\subsubsection{Measurement time}

A crucial element from the operational point of view is the Measurement time, intended not only as the time needed for performing 


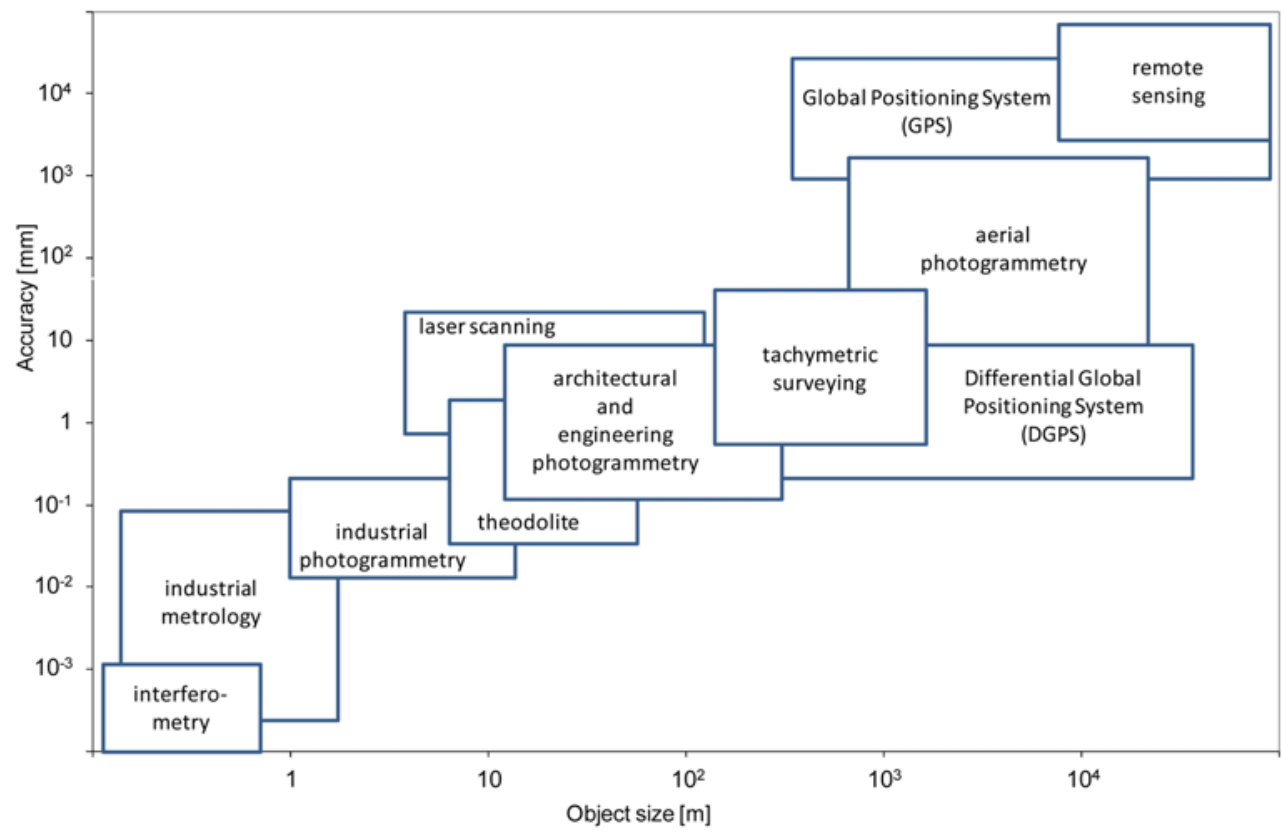

Fig. 4 Relationship between object size and accuracy for different LSDM technologies ${ }^{9,109}$ (with permission)

Table 6 Classification of major LSDM systems according to the criterion Measurement time

\begin{tabular}{cccc}
\hline Time & Positioning and setup & Calibration & Measurement \\
\hline Minutes & $\begin{array}{c}\text { Theodolites, photogrammetric systems, } \\
\text { MScMS-II, iGPS }\end{array}$ & $\begin{array}{c}\text { Theodolites, photogrammetric systems, } \\
\text { MScMS-II, iGPS }\end{array}$ & $\begin{array}{c}\text { Laser trackers, theodolites, } \\
\text { photogrammetric systems, } \\
\text { MScMS-II, iGPS }\end{array}$ \\
\hline Hours & Laser trackers total stations, HiBall, MScMS-I & Laser trackers total stations, HiBall, MScMS-I & CMM (gantry or horizontal-arm) \\
\hline Days & CMM (gantry or horizontal-arm) & CMM (gantry or horizontal-arm) & \\
\hline
\end{tabular}

a single measurement, but all the time necessary for the management of the instrument, including positioning and setup. For that reason many systems that, in principle, may generate a certain interest for their elevated metrological performances, often produce deep disappointment because of their long worm-up times. This is the case, for example, of past generation laser trackers. ${ }^{67,87,110}$ Other systems, even if they do not guarantee excellent levels of accuracy, are often preferred for their lower times of use and setup. Examples are photogrammetric systems and iGPS..$^{59,77,79}$ Table 6 reports a classification of the major LSDM systems according to their related Measurement times.

\subsection{Working part restrictions}

Together with Environmental restrictions, Working part restrictions is the basic perspective directly related to the working conditions. In fact though many systems present excellent metrological characteristics, they may show severe limits of application related to the measured object material and its surface finishing. For example, contact systems cannot be employed with soft or flexible surfaces. In some other cases, such as for example with many optical systems, the surface of the measured object must be opportunely treated with specific paints or covering in order to avoid reflections which may influence the measurement results. ${ }^{11}$

Another critical issue is the presence of holes, undercuts or internal zones. These features cannot be easily measured by all the systems, for example the optical ones show great problems in this kind of
Table 7 Criteria and element of evaluation for the perspective Working part restrictions

\begin{tabular}{|c|c|c|}
\hline & Criterion & Element of evaluation \\
\hline \multirow{4}{*}{4.3 .1} & \multirow{4}{*}{ - Material } & - rigid solid \\
\hline & & - soft/flexible solid \\
\hline & & - liquid \\
\hline & & - gas \\
\hline \multirow{7}{*}{4.3 .2} & \multirow{7}{*}{ - Surface quality } & - smooth \\
\hline & & - rough \\
\hline & & - matt \\
\hline & & - reflective \\
\hline & & - translucent \\
\hline & & - transparent \\
\hline & & - pre-treated \\
\hline \multirow[b]{2}{*}{4.3 .3} & \multirow{2}{*}{$\begin{array}{l}\text { - Accessibility } \\
\text { (location of } \\
\text { measured points) }\end{array}$} & - line of sight \\
\hline & & $\begin{array}{l}\text { - hidden points (hols, undercuts, } \\
\text { internal zones) }\end{array}$ \\
\hline
\end{tabular}

applications. $^{112}$

With reference to this perspective, three criteria of analysis are identified: Material, Surface quality, Accessibility (location of measured points) (see Table 7).

\subsubsection{Material}

This criterion refers to the mechanical properties of the measured object material. Considering that, during the measuring procedure, a 
Table 8 Criteria and scale categories for the perspective Environmental restrictions

\begin{tabular}{|c|c|c|}
\hline & Criterion & Scale categories \\
\hline \multirow{3}{*}{4.4 .1} & \multirow{3}{*}{$\begin{array}{l}\text { - Working } \\
\text { temperature }\end{array}$} & - under standard values \\
\hline & & - in standard values \\
\hline & & - over standard values \\
\hline \multirow{3}{*}{4.4 .2} & \multirow{3}{*}{ - Working humidity } & - under standard values \\
\hline & & - in standard values \\
\hline & & - over standard values \\
\hline \multirow{3}{*}{4.4 .3} & \multirow{3}{*}{ - Working pressure } & - under standard values \\
\hline & & - in standard values \\
\hline & & - over standard values \\
\hline \multirow{2}{*}{ 4.4.4 } & \multirow{2}{*}{ - Location } & - indoor \\
\hline & & - outdoor \\
\hline \multirow{6}{*}{4.4 .5} & \multirow{6}{*}{ - Noise factors } & - vibrations \\
\hline & & - air turbulence \\
\hline & & - sonic interference \\
\hline & & - ambient lighting \\
\hline & & - absence of atmosphere \\
\hline & & $\begin{array}{l}\text { - contamination (by smoke, gas, dust, } \\
\text { electromagnetic field and radioactivity) }\end{array}$ \\
\hline
\end{tabular}

probe or the measuring system itself must be brought into contact with the measured object, or a ray or a radio/US frequency must be reflected by its surface, the nature of the material may strongly affect the result of the measurement. ${ }^{107,113-116}$

According to this criterion, four levels of evaluation may be identified: rigid solid, soft/flexible solid, liquid, gas.

All contact systems are automatically excluded in case of soft/flexible solid, liquid and gas materials. Hence, for example, iGPS, which is usually considered a very accurate and versatile system, cannot be used for the measurement of liquid surfaces in tanks. ${ }^{17,118}$ On the contrary, US systems may be used for measuring the change of density or temperature in air or for flow analysis. ${ }^{119}$ Hence, they can be very helpful for mapping environment gradients in a given volume or space.

\subsubsection{Surface quality}

Surface quality concerns the level of finishing of the surface of the measured object. Usually, both for contact and non-contact system, rough surface finishing may compromise the whole measurement process, but for optical instrument this issue is even more critical. In fact, even when using contact optical systems, such as for example MScMS-II, surface reflections of light (or IR signal) may interfere with the measurement. ${ }^{9,65}$ This is the reason why, very often, optical systems need matt surfaces or specific pre-treatments of them before measurement. ${ }^{111}$ Furthermore, surface quality depends on the type of material considered. Smooth metal surfaces, reflective or transparent material are the most critical for optical systems. ${ }^{13}$

Seven element of evaluation may be identified: smooth, rough, matt, reflective, translucent, transparent, pre-treated. In particular, with the term pre-treated, it is intended that a surface must necessarily be treated in order to be measured by a given instrument.

\subsubsection{Accessibility}

This last criterion is related to the possibility of measuring holes, undercuts or internal zones. This is often a critical drawback for optical systems, which work well only if the measured points are positioned in line of sight with respect to the sensors.

According to this criterion, two element of discrimination can be defined: line of sight, hidden points (hols, undercuts, internal zones).

Usually, most of the LSDM systems need a direct line of sight between sensors and measured point, however, the use of specific probes may help to overcome the problem of measuring small holes and cavities. This is the case, for example, of CMMs and MScMS-II or specific optical systems. ${ }^{65,81,112}$

On the contrary, it must be highlighted that in case of distributed systems, such as for example iGPS, MScMS-I, MScMS-II or photogrammetry, only a subset of sensors must be on the line of sight of the measured object, and this represents the major potential of this kind of systems. ${ }^{63-65,77}$

\subsection{Environmental restrictions}

Environmental restrictions are strictly connected to the specific field of application. They define the environmental conditions in which the system may be employed. This perspective, for example, considers if a system can be used indoor or outdoor, or if it is suitable for nonstandard conditions of temperature, humidity, contamination, etc. ${ }^{120-122}$

According to this perspective, five criteria of analysis are defined: Working temperature, Working humidity, Working pressure, Location and Noise factors (see Table 8).

\subsection{1,2,3 Working temperature, working humidity and working pressure}

These three criteria refer to the typical variables of influence during measurement. All the most diffused systems for LSDM (see Table 4) are designed for standard conditions. That means that they should be used with caution out of these limits. This is one of the main drawbacks of these systems for their employment out of laboratories. In the scientific literature, approaches for special applications, such as for example underwater measurements or similar, are often discussed. ${ }^{120-123}$

For each of these criteria, three element of discrimination can be defined: under standard values, in standard values, over standard values.

\subsubsection{Location}

Location explicitly defines if a given system may be used indoor or outdoor. This criterion sums up all the implications related to the employment of the system in the various environmental conditions. Due to their principal laboratory application, all the main systems for LSDM here considered are designed for indoor applications, except for same rare cases, in which external conditions are therefore kept under strict control. Nevertheless, there are some example of outdoor applications, especially for surveying big mechanical structures, aerospace, construction, architectural and archaeological applications. ${ }^{1,15,23,29,30,32,105,116}$

\subsubsection{Noise factors}

Noise factors is a criterion which is worth discussing accurately. It includes all that factors, which may affect the result of a measurement. According to the dominant technology criterion, each system may be more or less sensitive to one or more disturbing elements. A nonexhaustive list of noise factors involves (see Table 8): vibrations, air turbulence, sonic interference, ambient lighting, absence of atmosphere, 
Table 9 Criteria and scale categories for the perspective Use conditions

\begin{tabular}{|c|c|c|}
\hline & Criterion & Scale categories \\
\hline 4.5 .1 & - Cost & $\begin{array}{l}\text { - purchasing, installation and } \\
\text { maintenance cost }\end{array}$ \\
\hline \multirow{9}{*}{ 4.5.2 } & \multirow{9}{*}{$\begin{array}{l}\text { - Supported } \\
\text { software }\end{array}$} & - GUI interface \\
\hline & & - coordinate measurement \\
\hline & & $\begin{array}{l}\text { - basic geometric measurements } \\
\text { (distances, geometrical figures, etc.) }\end{array}$ \\
\hline & & - tolerance verification \\
\hline & & - evaluation of measurement uncertainty \\
\hline & & - self-calibration \\
\hline & & - self-diagnostic \\
\hline & & $\begin{array}{l}\text { - self-detection self-compensation and } \\
\text { self-correction of errors }\end{array}$ \\
\hline & & $\begin{array}{l}\text { - compatibility with other software } \\
\text { (CAD, CAE, etc.) }\end{array}$ \\
\hline \multirow{6}{*}{4.5 .3} & \multirow{6}{*}{ - Standards } & - construction \\
\hline & & - setup \\
\hline & & - use and storage \\
\hline & & - calibration \\
\hline & & - uncertainty evaluation \\
\hline & & - error correction/compensation \\
\hline \multirow{6}{*}{ 4.5.4 } & \multirow{6}{*}{ - Application fields } & - construction (industrial and housing) \\
\hline & & $\begin{array}{l}\text { - large mechanical structures } \\
\text { (telescopes, tanks, etc.) }\end{array}$ \\
\hline & & - automotive \\
\hline & & - shipbuilding \\
\hline & & - aeronautic \\
\hline & & - aerospace \\
\hline \multirow{4}{*}{ 4.5.5 } & \multirow{4}{*}{ - System diffusion } & - not used \\
\hline & & - rarely used \\
\hline & & - used \\
\hline & & - very used \\
\hline \multirow{4}{*}{ 4.5.6 } & \multirow{4}{*}{$\begin{array}{l}\text { - Technological } \\
\text { obsolescence }\end{array}$} & - obsolete \\
\hline & & - becoming obsolete \\
\hline & & - actual \\
\hline & & - future \\
\hline \multirow{3}{*}{4.5 .7} & \multirow{3}{*}{$\begin{array}{l}\text { - Technological } \\
\text { complexity }\end{array}$} & - low \\
\hline & & - medium \\
\hline & & - high \\
\hline \multirow{4}{*}{ 4.5.8 } & \multirow{4}{*}{$\begin{array}{l}\text { - Ergonomics } \\
\text { (easiness of use) }\end{array}$} & - portability \\
\hline & & - flexibility \\
\hline & & - handiness \\
\hline & & - scalability \\
\hline
\end{tabular}

contamination (by smoke, gas, dust, electromagnetic field and radioactivity).

For example, systems based on US waves are very sensitive to sonic interference; on the contrary, systems using light/IR waves suffer ambient lighting. Many studies showed that optical systems, as well as sonic ones, are strongly affected by air turbulence and unevenness. ${ }^{9,124}$ Also dust contamination is the Achille's heel of the large part of the most diffused systems.

\subsection{Use conditions}

Use conditions is the perspective which includes all the elements related to the procurement and application of the system. Eight elements of discrimination are defined (see Table 9): Cost, Supported software, Standards, Application fields, System diffusion, Technological obsolescence, Technological complexity, Ergonomics (easiness of use).

\subsubsection{Cost}

Cost is one of the basic criteria, as well as the metrological performance, in the choice between two or more LSDM systems. ${ }^{7,34,35,90}$ Even if it includes cost of acquisition and maintenance, it must be said that the cost of acquisition is the most significant and, in many cases, reaches hundreds of thousands of Euros.

Table 10 reports a classification of the most diffused optical LSDM systems on the bases of Costs, Total accuracy (discussed in Section 4.2.1) and Ergonomics (discussed in Section 4.5.8).

\subsubsection{Supported software}

The basic information that a LSDM system may provide is either the Cartesian coordinates of a measured point or the measure of a geometrical feature (i.e. a distance or an angle). ${ }^{1,89}$ However, many system are equipped by specific software for data elaboration, in order to provide further information such as for example the features of specific geometrical figures, or to perform advanced calibration, set-up and self-diagnostic operations. ${ }^{125-131}$

Furthermore, the possibility to interact with other systems, instruments or external software, is an important key-element for the use in factories and laboratories. ${ }^{19,37,132-134}$ In many practical applications, collected measurements are used for the verification of geometrical tolerances, reverse engineering, surfaces analysis, etc. The interface with specific CAD software is mandatory for these applications. ${ }^{135}$

Basic elements to deploy this criterion are: GUI (Graphic User Interface), coordinate measurement, basic geometric measurements (distances, geometrical figures, etc.), tolerance verification, evaluation of measurement uncertainty, self-calibration, self-diagnostic, selfdetection, self-compensation and self-correction of errors, compatibility with other software (CAD, CAE, etc.).

\subsubsection{Standards}

In the field of LSDM there is still a considerable lack of standards. The reasons are both related to the heterogeneity of instruments and to the fact that these last years have seen a massive introduction of new systems based on optical technology. ${ }^{8}$

Actually, the main reference standards for LSDM are related to CMMs or, in general, to systems for dimensional measurements ${ }^{136-140}$ or to optical systems. ${ }^{141,142}$ However, the arising interest towards LSDM in the last ten years is attested by the development of some specific standards, such as for example, ASME B89.4.19:2006 for laser trackers and the German guideline VDI/VDE 2634:2002 for photogrammetry. Referring to the current scientific literature, many papers try to give indications and prescription for system evaluation, calibration, traceability and uncertainty evaluation. For this last case, the reference standard is the "Guide to the expression of uncertainty in measurement". $64,109,124,130$, 143-154

In detail, six elements are considered for the analysis: construction, setup, use and storage, calibration, uncertainty evaluation, error correction/ compensation.

\subsubsection{Application fields}

Application field is another important element of distinction for 
Table 10 Qualitative comparison of optical-based distributed systems for Large-Scale Metrology. The last column reports a rough estimation of the economic impact (referred to the purchasing cost), expressed in $k €$. The wide range of variation of costs is related to the fact that different manufacturers offer metrology instruments with different performance levels and accessories. ${ }^{*}$ ) It has to be noted that the economic impact of the two distributed systems (Indoor-GPS and MScMS-II) is strongly related to the network sizing, i.e. the number of remote sensor devices. The reported values refer to the minimum number of sensors needed to perform network calibration (i.e. three sensing units) ${ }^{63}$

\begin{tabular}{|c|c|c|c|c|c|c|}
\hline \multirow{3}{*}{ System } & \multicolumn{6}{|c|}{ Criteria } \\
\hline & \multicolumn{3}{|c|}{ ergonomics } & \multirow{2}{*}{ scalability } & \multirow{2}{*}{ total accuracy } & \multirow{2}{*}{ purchasing cost $[\mathrm{k} €]$} \\
\hline & portability & flexibility & handiness & & & \\
\hline Laser tracker & medium & medium & medium & low & high & $80-150$ \\
\hline Laser radar & medium & medium & medium & low & high & $400-500$ \\
\hline Digital photogrammetry & high & medium & high & medium & high & $20-100$ \\
\hline Indoor GPS & high & high & medium & high & high & $>150(*)$ \\
\hline MScMS - II & high & high & high & high & medium & $>3(*)$ \\
\hline
\end{tabular}

Table 11 Classification of major LSDM systems according to the criteria System diffusion and Technological obsolescence

\begin{tabular}{|c|c|c|c|c|}
\hline & Not used & Rarely used & Used & Very used \\
\hline Obsolete & & Tapes, wires and sticks & & \\
\hline Becoming obsolete & & & & Theodolite \\
\hline Actual & & $\begin{array}{l}\text { Photogrammetry, tacheometer, } \\
\text { camera based triangulation }\end{array}$ & $\begin{array}{l}\text { Total station, CMM, } \\
\text { optical probe CMM }\end{array}$ & Laser tracker \\
\hline Future & HiBall, MScMS-I, MScMS-II & $\begin{array}{l}\text { Contact and non-contact systems with } \\
\text { multilateration technique, iGPS, laser radar }\end{array}$ & Total stations & \\
\hline
\end{tabular}

LSDM systems. As highlighted in the previous Sections, application fields range from archaeology to aerospace. In many cases, the versatility implies the possibility of using the system in different environmental conditions. The main application fields for LSDM systems are: construction (industrial and housing), large mechanical structures (telescopes, tanks, etc.), automotive, shipbuilding, aeronautic, aerospace.

\subsubsection{System diffusion}

This criterion is related to the diffusion of technologies. Many systems, although technologically advanced and with high metrological performance, are not so diffused as expected. Sometimes the reasons must be found in other criteria such as for example Cost, Ergonomics, etc., which must be better investigated and deepened. Scale categories of this criterion are: not used, rarely used, used, very used. The major LSDM systems are classified in Table 11 according to this criterion as well as Technological obsolescence.

\subsubsection{Technological obsolescence}

Technological obsolescence is a criterion useful to indicate the ageing of a technology. Usually the Technological obsolescence is also associated to low metrological performance, complexity in use and poor interfacing with other automatic systems. Scale categories are: obsolete, becoming obsolete, actual, future.

As an example, Table 11 presents the major LSDM systems classified according to the criteria System diffusion and Technological obsolescence.

\subsubsection{Technological complexity}

Technological complexity is a criterion considered in the choice of a system. This is also correlated to the complexity of use and the versatility. A system can be defined as technological complex if it is made up of multiple technologically advanced components, which interact with each other and with other systems. Even if this condition might mean high and innovative performance, it often may imply a reduction of reliability, difficulty in repair and maintenance, complexity in set-up and use. In this way, often high technological components may result in source of troubles during system application. In the present analysis the concept of Technological complexity is intended in this negative acceptation. Scale categories are: high, medium, low.

\subsubsection{Ergonomics (easiness of use)}

This criterion is directly related to the easiness of use. It may entail specific training of the operator.

In particular, Ergonomics includes: ${ }^{65,81}$

portability: it is intended as the capability of the system to be easily moved within the working environment;

flexibility: it refers to system capabilities to apply to different working environments and to perform various measurement tasks;

handiness: it means easiness of installation and use;

scalability: it refers to the capability to cover differently sized and shaped volumes.

Table 10 reports a classification of the most diffused optical LSDM systems on the basis of Ergonomics, as well as Costs (discussed in Section 4.5.1) and Total accuracy.

\section{Using the LSDM Multi-perspective Model}

The global reference model (LSDM Multi-perspective Model) proposed in this paper is synthetized in Figs. 5(a) and 5(b) with an example of application to iGPS. All the five perspectives are deployed into their resultant criteria, and the system is analyzed according to each of them. Circles drawn in Figs. 5(a) and 5(b) identify the criteria satisfied by the system. If required, a quantitative evaluation is reported 


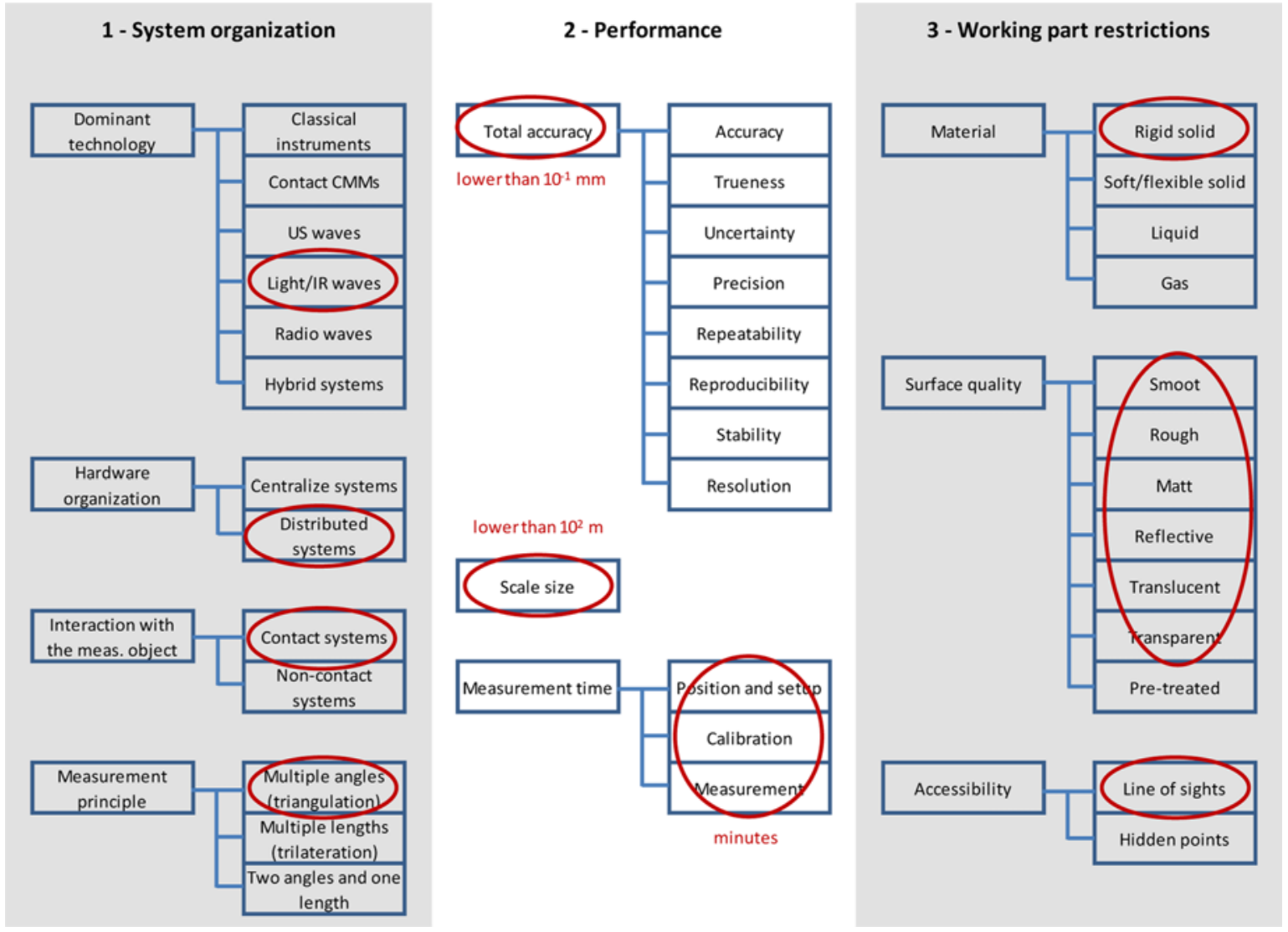

Fig. 5(a) Global scheme (perspectives 1, 2 and 3) of the reference model proposed in this paper for LSDM systems taxonomy. Circles identify the criteria satisfied by iGPS. If required, a quantitative evaluation is reported under the corresponding criterion

under the corresponding criterion (such as for example, in the case of criteria: Total accuracy or Scale size).

This model can be used as a tool for individuating possible lack of coverage for particular applications or working conditions. It may represent a sort of guiding framework for the design of new and more effective systems, as well as a scheme for the analysis of already existing ones.

According to this approach, the model can be also seen as a road map for analyzing new and existing systems, and for defining which is most appropriate for each specific application case. All the perspectives must be considered equally important from this point of view, but interpreted according to the case at hand.

The model can be enriched by new technologies as they are discovered and it can be a reference for the introduction of new ones.

For example, when a new technology is introduced, the potentiality of a new system may be analysed according to each criterion and it can be compared to the existing ones. On the contrary, if some lack exists, the model is able to identify it. It provides a reference structure for studying and enriching the basic architecture in order to satisfy the whole set of criteria.

From the application point of view, the LSDM Multi-perspective Model allows the following two actions:

1) Analysis and classification of existing systems

The model provides a reference background to recognize all the main characteristics of a system (see, for example, Figs. $5 \mathrm{a}$ and $5 \mathrm{~b}$ for iGPS) and to compare it with other systems with the aim of:
- identifying elements for improvement,

- choosing the most appropriate system for a given application,

- identifying lacks or criticalities.

2) Study and propose of new systems

The model provides a framework for:

- identifying and analysing the lacks in the satisfaction of the criteria by the existing systems,

- evaluating new ideas for the development of new systems.

\section{Final Remarks and a Perspective Vision of the Future}

The survey proposed in this paper presents a general framework for the analysis and classification of LSDM systems. The main novelties in comparison to similar approaches reported in literature are:

- the study of the state of the art of LSDM, also based on a deep bibliometric analysis of the recent literature in the field and on the study of the patents issued in the last decades;

- a taxonomy based on the introduction of five perspectives of analysis, which permits a rigorous classification starting from the working principles till to the field of application and the constraints of use,

- the possibility to use the proposed framework both for the analysis and classification of existing systems (in order to give a guide for choosing the most appropriate system or instrument according to the measuring needs) and for the study of new ones 

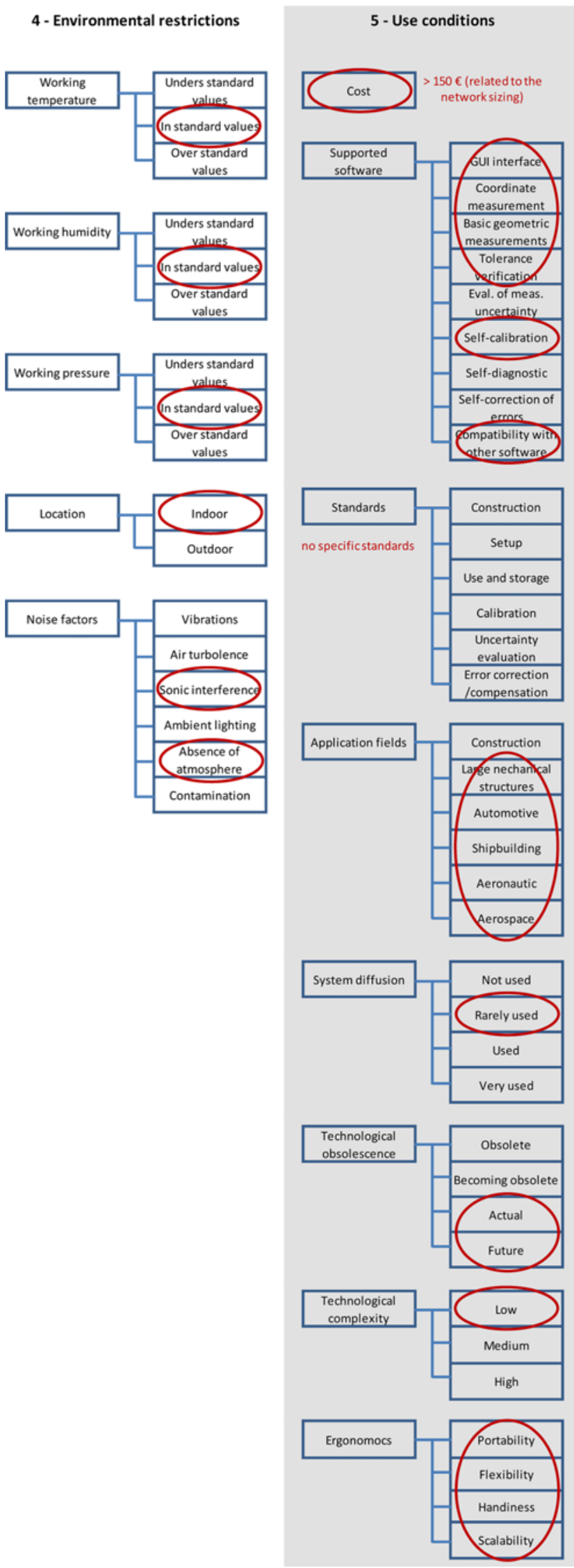

Fig. 5(b) Global scheme (perspectives 4 and 5) of the reference model proposed in this paper for LSDM systems taxonomy. Circles identify the criteria satisfied by iGPS. If required, a quantitative evaluation is reported under the corresponding criterion according to emerging technologies.

In particular, the bibliographic and patent analysis about LSDM has shown a strong evolution of systems, especially in the last ten years. Considering the dominant technologies, most attention is paid to optical system, with special interest on laser-interferometry technology, strictly followed by photogrammetry and structured-light scanning. ${ }^{67}$

From the analysis of patents, scientific literature and technological state of the art, three main elements seem to drive the roadmap for the future:

- Systems are ever more "intelligent", they integrates software procedures for data acquisition and elaboration, set-up, selfdiagnostics, surface reconstruction, control of tolerances, etc. Furthermore many complementary software allow the integration with other applications (for example, CAD, CAM, CAE, etc.), or with Augmented Reality (AR) applications in order to guide the operator during the measurement procedure.

- Trend of new systems is toward multi-sensor architectures, even based on different technologies, in order to self-correct, selfcompensate and cooperate. The application of data-fusion techniques is taking a great contribution to the implementation of systems distributed around the working volume of the object to be measured.

- Integration with the whole production system in the so called "smart manufacturing / smart factory". The aim is to achieve completely automated systems, even for the measurement activity. The vision is to obtain "self-measuring systems", with a complete permeation between the measured object and the measuring system.

Many challenges remain still open, ranging from the need of ever more versatile and easy to use systems to the need of a complete and sweeping system of standards.

The literature and patent analysis has shown an explosion of interest around the optical systems, but, despite their great level of accuracy and easiness of use, they still suffer from some technical problems related to the surface characteristics and to the environmental conditions.

\section{REFERENCES}

1. Purttock, M. J., "Large-Scale Metrology,” CIRP Annals, Vol. 21, No. 2, pp. 351-356 1978.

2. Swyt, D. A., "Length and Dimensional Measurements at NIST," Journal of Research-National Institute of Standards and Technology, Vol. 106, No. 1, pp. 1-24, 2001.

3. Estler, W. T., Edmundson, K. L., Peggs, G. N., and Parker, D. H., "Large-Scale Metrology-an Update," CIRP Annals-Manufacturing Technology, Vol. 51, No. 2, pp. 587-609, 2002.

4. Weckenmann, A., Estler, T., Peggs, G., and McMurtry, D., "Probing Systems in Dimensional Metrology," CIRP Annals-Manufacturing Technology, Vol. 53, No. 2, pp. 657-684, 2004.

5. Hughes, B., "Large Scale Metrology at NPL," Proc. of the Large Scale Metrology Workshop, 2006. 
6. Cuypers, W., Van Gestel, N., Voet, A., Kruth, J. P., Mingneau, J., and Bleys, P., "Optical Measurement Techniques for Mobile and Large-Scale Dimensional Metrology," Optics and Lasers in Engineering, Vol. 47, No. 3-4, pp. 292-300, 2009.

7. Cuypers, W., Van Gestel, N., Voet, A., Kruth, J. P., Mingneau, J., and Bleys, P., "Optical Measurement Techniques for Mobile and Large-Scale Dimensional Metrology," Optics and Lasers in Engineering, Vol. 47, No. 3, pp. 292-300, 2009.

8. Peggs, G., Maropoulos, P. G., Hughes, E., Forbes, A., Robson, S., Ziebart, M., and Muralikrishnan, B., "Recent Developments in Large-Scale Dimensional Metrology," Proceedings of the Institution of Mechanical Engineers, Part B: Journal of Engineering Manufacture, Vol. 223, No. 6, pp. 571-595, 2009.

9. Franceschini, F., Galetto, M., Maisano, D., Mastrogiacomo, L., and Pralio, B., "Distributed Large-Scale Dimensional Metrology," Springer, 2011.

10. Burner, A. W., Radeztsky, R. H., and Liu, T., "Videometric Applications in Wind Tunnels," Proc. of SPIE, Vol. 3174, pp. 234$247,1997$.

11. Kugel, H. W., Loesser, D., Roquemore, A. L., Menon, M. M., and Barry, R. E., "Precision Metrology of NSTX Surfaces using Coherent Laser Radar Ranging," Review of Scientific Instruments, Vol. 72, No. 1, pp. 533-536, 2001

12. Jones, T. W. and Pappa, R. S., "Dot Projection Photogrammetric Technique for Shape Measurements of Aerospace Test Articles," Proc. of 40th AIAA Aplied Aerodynamics Conference, AIAA 2002-0532, 2002.

13. Jones, T. W., Dorrington, A. A., Brittman, P. L., and Danehy, P. M., "Laser Induced Fluorescence for Photogrammetric Measurement of Transparent or Reflective Aerospace Structures," Proc. of 49th Annual International Instrumentation Symposium, 2003.

14. Scopigno, R., Cignoni, P., Callieri, M., Ganovelli, F., Impoco, G., et al., "Using Optically Scanned 3D Data in the Restoration of Michelangelo's David,” Proc. of SPIE, Vol. 5146, pp. 44-53, 2003.

15. Balsamo, A., Chimienti, A., Desogus, S., Grattoni, P., Meda, A., et al., "A Portable Stereovision System for Cultural Heritage Monitoring," CIRP Annals-Manufacturing Technology, Vol. 54, No. 1, pp. 499-502, 2005.

16. Hand, S. D., Clark, J. F. F., Mongon, W. J., and Schindelholz, E., "Measurement of the USS Monitor Propeller using Structured Light and Coherent Laser Radar Scanning Technologies," Proc. of the CMSC 2005 Coordinate Systems Measurement Conference, 2005.

17. Reichold, A., Dawson, M., Green, J., Han, Y., Jones, M., et al., "The LiCAS-RTRS-A Rapid and Cost Efficient Survey System for the ILC," Proc. of the 9th International Workshop on Accelerator Alignment, 2006

18. Cai, B., Guo, Y., Jamshidi, J., and Maropoulos, P., "Measurability Analysis Of Large Volume Metrology Process Model For Early Design," Proc. of 5th International Conference on Digital Enterprise
Technology, 2008.

19. Maropoulos, P. G., Guo, Y., Jamshidi, J., and Cai, B., "Large Volume Metrology Process Models: A Framework for Integrating Measurement with Assembly Planning," CIRP AnnalsManufacturing Technology, Vol. 57, No. 1, pp. 477-480, 2008.

20. Jamshidi, J., Kayani, A., Iravani, P., Maropoulos, P. G., and Summers, M., "Manufacturing and Assembly Automation by Integrated Metrology Systems for Aircraft Wing Fabrication," Proc. of the Institution of Mechanical Engineers, Part B: Journal of Engineering Manufacture, Vol. 224, No. 1, pp. 25-36, 2010.

21. Cuesta, E., Álvarez, B. J., Sánchez-Lasheras, F., Fernández, R. L., and Gonzalez-Madruga, D., "Feasibility Evaluation of Photogrammetry versus Coordinate Measuring Arms for the Assembly of Welded Structures," Advanced Materials Research, Vol. 498, pp. 103-108, 2012.

22. Flynn, R., "Synthesizing Metrology Technologies to Reduce Engineering Time for Large CNC Machine Compensation," SAE International Journal of Materials and Manufacturing, Vol. 5, No. 1, pp. 49-59, 2011.

23. Goch, G., Knapp, W., and Härtig, F., "Precision Engineering for Wind Energy Systems," CIRP Annals-Manufacturing Technology, Vol. 61, No. 2, pp. 611-634, 2012.

24. Liu, T., Burner, A. W., Jones, T. W., and Barrows, D. A., "Photogrammetric Techniques for Aerospace Applications," Progress in Aerospace Sciences, Vol. 54, pp. 1-58, 2012.

25. Nüchter, A., Surmann, H., Lingemann, K., and Hertzberg, J., "Consistent 3D Model Construction with Autonomous Mobile Robots," Advances in Artificial Intelligence, vol. 2821, pp. 550564, 2003.

26. Galetto, M., Mastrogiacomo, L., Pralio, B., and Spagnolo, C., "Indoor Environmental Mapping by Means of Autonomous Guided Agents," Proc. of ASME 2010 10th Biennial Conference on Engineering Systems Design and Analysis, Paper No. ESDA201025224, pp. 759-767, 2010.

27. Santolaria, J., Conte, J., and Ginés, M., "Laser Tracker-Based Kinematic Parameter Calibration of Industrial Robots by Improved CPA Method and Active Retroreflector," The International Journal of Advanced Manufacturing Technology, Vol. 66, No. 9-12, pp. 2087-2106, 2013.

28. Taylor, J., Beraldin, J.-A., Godin, G., Cournoyer, L., Baribeau, R., et al., "NRC 3D Imaging Technology for Museum and Heritage Applications," The Journal of Visualization and Computer Animation, Vol. 14, No. 3, pp. 121-138, 2003.

29. Blais, F. and Beraldin, J.-A., "Recent Developments in 3D MultiModal Laser Imaging Applied to Cultural Heritage," Machine Vision and Applications, Vol. 17, No. 6, pp. 395-409, 2006.

30. Guidi, G., Frischer, B., Russo, M., Spinetti, A., Carosso, L., and Micoli, L. L., "Three-Dimensional Acquisition of Large and Detailed Cultural Heritage Objects," Machine Vision and Applications, Vol. 
17, no. 6, pp. 349-360, 2006

31. Atwater, F., Hand, D., Hardin, H., Edwards, W., and Chamsine, G., "The Measurement and Modeling of a World War I Mark IV Tank Using CLR and CCD Camera/Line Scanning Systems in an Outside Environment," Journal of the CMSC, Vol. 2, No. 2, pp. 4-10, 2007.

32. Stiros, S. C., "Levelling in Antiquity: Instrumentation, Techniques and Accuracies," Survey Review, Vol. 44, No. 324, pp. 45-52, 2012.

33. Norman, A. R., Schönberg, A., Gorlach, I. A., and Schmitt, R., "Validation of iGPS as an External Measurement System for Cooperative Robot Positioning," The International Journal of Advanced Manufacturing Technology, Vol. 64, No. 1-4, pp. 427446, 2013.

34. Saadat, M. and Cretin, C., "Dimensional Variations during Airbus Wing Assembly," Assembly Automation, Vol. 22, No. 3, pp. 270276, 2002.

35. Saadat, M. and Cretin, L., "Measurement Systems for Large Aerospace Components," Sensor Review, Vol. 22, No. 3, pp. 199206, 2002.

36. Maropoulos, P. G., Zhang, D., Rolt, S., Chapman, P., and Rogers, B., "Integration of Measurement Planning with Aggregate Product Modelling for Spacecraft Design and Assembly," Proc. of the Institution of Mechanical Engineers, Part B: Journal of Engineering Manufacture, Vol. 220, No. 10, pp. 1687-1695, 2006.

37. Maropoulos, P. G., Zhang, D., Chapman, P., Bramall, D. G., and Rogers, B. C., "Key Digital Enterprise Technology Methods for Large Volume Metrology and Assembly Integration,” International Journal of Production Research, Vol. 45, No. 7, pp. 1539-1559, 2007.

38. Muelaner, J. E. and Maropoulos, P., "Large Scale Metrology in Aerospace Assembly," Proc. of 5th International Conference on Digital Enterprise Technology, 2008.

39. Kim, K., Lee, S., Kim, K., Lee, K.-Y., Heo, S., et al., "Development of the End-Effector Measurement System for a 6-Axis Welding Robot,” Int. J. Precis. Eng. Manuf., Vol. 11, No. 4, pp. 519-526, 2010 .

40. Mbarek, T., Meissner, A., and Biyiklioglu, N., "Positioning System for the Aircraft Structural Assembly," SAE International Journal of Aerospace, Vol. 4, No. 2, pp. 1038-1047, 2011.

41. Liu, S., Luo, Z., Tan, G., Ye, N., and Zhang, L., "3D Measurement and Quality Evaluation for Complex Aircraft Assemblies," Acta Aeronautica ET Astronautica Sinica, No. 2, pp. 409-418, 2013.

42. Savio, E., De Chiffre, L., and Schmitt, R., "Metrology of Freeform Shaped Parts," CIRP Annals-Manufacturing Technology, Vol. 56, No. 2, pp. 810-835, 2007.

43. Huber, D. F. and Hebert, M., "Fully Automatic Registration of Multiple 3D Data Sets," Image and Vision Computing, Vol. 21, No. 7, pp. 637-650, 2003.

44. Mitchell, J. P., Spence, A. D., Hoang, M., and Free, A., "Sensor Fusion of Laser Trackers for use in Large-Scale Precision
Metrology," Proc. of SPIE, Intelligent Manufacturing, Vol. 5263, pp. 57-65, 2004.

45. Zexiao, X., Jianguo, W., and Qiumei, Z., "Complete 3D Measurement in Reverse Engineering using a Multi-Probe System," International Journal of Machine Tools and Manufacture, Vol. 45, No. 12, pp. 1474-1486, 2005.

46. Jamshidi, J., Owen, G. W., and Mileham, A. R., "A New Data Fusion Method for Scanned Models," Journal of Computing and Information Science in Engineering, Vol. 6, No. 4, pp. 340-348, 2006.

47. Weckenmann, A., Jiang, X., Sommer, K.-D., Neuschaefer-Rube, U., Seewig, J., et al., "Multisensor Data Fusion in Dimensional Metrology," CIRP Annals-Manufacturing Technology, Vol. 58, No. 2, pp. 701-721, 2009.

48. Forbes, A. B., "Weighting Observations from Multi-Sensor Coordinate Measuring Systems," Measurement Science and Technology, Vol. 23, No. 2, Paper No. 025004, 2012.

49. Wendt, K., Franke, M., and Härtig, F., "Measuring Large 3D Structures using Four Portable Tracking Laser Interferometers," Measurement, Vol. 45, No. 10, pp. 2339-2345, 2012.

50. Senin, N., Colosimo, B. M., and Pacella, M., "Point Set Augmentation through Fitting for Enhanced ICP Registration of Point Clouds in Multisensor Coordinate Metrology," Robotics and Computer-Integrated Manufacturing, Vol. 29, No. 1, pp. 39-52, 2013.

51. White, D. A., "Coherent laser Radar: True Noncontact 3-D Measurement Has Arrived - This New 3-D Measurement Technology Eliminates the Need for Photogrammetry Dots, Laser Tracker SMRs or Hand-Held Probes," Quality Digest, Vol. 19, pp. 35-38, 1999.

52. Huntley, J. M., “Optical Shape Measurement Technology: Past, Present, and Future," Proc. of Symposium on Applied Photonics, pp. 162-173, 2000.

53. Chen, F., Brown, G. M., and Song, M., "Overview of ThreeDimensional Shape Measurement using Optical Methods," Optical Engineering, Vol. 39, No. 1, pp. 10-22, 2000.

54. Chow, J., Xu, T., Lee, S. -M., and Kengkool, K., "Development of an Integrated Laser-based Reverse Engineering and Machining System," The International Journal of Advanced Manufacturing Technology, Vol. 19, No. 3, pp. 186-191, 2002.

55. Gordon, S., Lichti, D. D., Stewart, M. P., and Tsakiri, M., "Metric Performance of a High-Resolution Laser Scanner," Proc. of APIE, Videometrics and Optical Methods for 3D Shape Measurement, Vol. 4309, pp. 174-184, 2001.

56. Schwenke, H., Neuschaefer-Rube, U., Pfeifer, T., and Kunzmann, H., "Optical Methods for Dimensional Metrology in Production Engineering," CIRP Annals-Manufacturing Technology, Vol. 51, No. 2, pp. 685-699, 2002.

57. Ribo, M. and Brandner, M., "State of the Art on Vision-based 
Structured Light Systems for 3D Measurements," Proc. of International Workshop on Robotic Sensors: Robotic and Sensor Environments, pp. 2-6, 2005.

58. Fan, Q., Chen, D. W., and Xi, J. T., "A High Precision 3D Laser Scanner System and Its Application,” Journal of Shanghai Jiaotong University, Col. 40, No. 2, pp. 227-230, 2006.

59. Luhmann, T., Robson ,S., Kyle, S., and Harley, I., "Close Range Photogrammetry: Principles, Techniques and Applications," Wiley, 2006.

60. Fryer, J. G., Mitchell, H. L., and Chandler, J. H., "Applications of 3D Measurement from Images,” Whittles Publishing, 2007.

61. Kyle, S., "Optically Jointed Probing Systems for Large Volume Coordinate Metrology," Journal of the CMSC, Vol. 2, No. 1, pp. 26-32, 2007.

62. Blanckaert, T. S. P., Metris, N., and Metris, L. B., "Frequency Modulated Coherent Laser Radar Technology," Proc. of 3rd Workshop on Optical Measurement Techniques, pp. 386-391, 2007.

63. Galetto, M., Mastrogiacomo, L., and Pralio, B., "A Wireless Sensor Network-based Approach to Large-Scale Dimensional Metrology," International Journal of Computer Integrated Manufacturing, Vol. 23, No. 12, pp. 1082-1094, 2010.

64. Galetto, M., Mastrogiacomo, L., and Pralio, B., "The Mobile Spatial Coordinate Measuring System II (MScMS-II): System Description and Preliminary Assessment of the Measurement Uncertainty," International Journal of Metrology and Quality Engineering, Vol. 1, No. 2, pp. 111-119, 2010.

65. Galetto, M., Mastrogiacomo, L., and Pralio, B., "MScMS-II: an Innovative IR-based Indoor Coordinate Measuring System for Large-Scale Metrology Applications," The International Journal of Advanced Manufacturing Technology, Vol. 52, No. 1-4, pp. 291302, 2011.

66. Questel, “Orbit,” http://www.questel.com/prodsandservices/Orbit. htm.html (Accessed 2 JUN 2014)

67. Franceschini, F. and Maisano, D., "The Evolution of Large-Scale Dimensional Metrology from the Perspective of Scientific Articles and Patents," The International Journal of Advanced Manufacturing Technology, Vol. 70, No. 5-8, pp. 887-909, 2014.

68. Hocken, R. J. and Lau, K. C., "Three and Five Axis Laser Tracking Systems," US Patent, No. 4714339A, 1987.

69. API Automated Precision Inc., http://www.apisensor.com/ (Accessed 18 JUL 2014).

70. FARO, http://www.faro.com/en-us/home (Accessed 18 JUL 2014).

71. Leica Geosystems, http://www.leica-geosystems.com/en/index.htm (Accessed 18 JUL 2014).

72. Nikon Metrology NV, http://www.nikonmetrology.com/en_EU/ (Accessed 18 JUL 2014).
73. Franceschini, F., Maisano, D., and Mastrogiacomo, L., "Mobile Spatial Coordinate Measuring System (MScMS) and CMMs: a Structured Comparison," The International Journal of Advanced Manufacturing Technology, Vol. 42, No. 11-12, pp. 1089-1102, 2009.

74. Hexagon, http://www.hexagon.com/en/index.htm (Accessed 18 JUL 2014).

75. Konica Minolta, http://www.konicaminolta.com/ (Accessed $18 \mathrm{JUL}$ 2014).

76. Muelaner, J. E., Wang, Z., Jamshidi, J., Maropoulos, P., Mileham, A. R., et al., "iGPS-An Initial Assessment of Technical and Deployment Capability," Proc. of 3rd International Conference on Manufacturing Engineering, pp. 805-810, 2008.

77. Maisano, D. A., Jamshidi, J., Franceschini, F., Maropoulos, P. G., Mastrogiacomo, L., et al., "A Comparison of Two Distributed LargeVolume Measurement Systems: the Mobile Spatial Co-Ordinate Measuring System and the Indoor Global Positioning System," Proc. of the Institution of Mechanical Engineers, Part B: Journal of Engineering Manufacture, Vol. 223, No. 5, pp. 511-521, 2009.

78. Schmitt, R., Nisch, S., Schonberg, A., Demeester, F., and Renders, S., "Performance Evaluation of iGPS for Industrial Applications," Proc. of International Conference on Indoor Positioning and Indoor Navigation (IPIN), pp. 1-8, 2010.

79. Du, F. Z., Chen, Z. H., and Tang, X. Q., "Precision Analysis of iGPS Measurement Field and its Application," Acta Aeronaut Astronaut Sinica, Vol. 33, No. 9, pp. 101-109, 2012.

80. Mermelstein, M. S., Feldkhun, D. L., and Shirley, L. G., "VideoRate Surface Profiling with Acousto-Optic Accordion Fringe Interferometry," Optical Engineering, Vol. 39, No. 1, pp. 106-113, 2000 .

81. Franceschini, F., Galetto, M., Maisano, D., and Mastrogiacomo, L., "Mobile Spatial Coordinate Measuring System (MScMS)Introduction to the System," International Journal of Production Research, Vol. 47, No. 14, pp. 3867-3889, 2009.

82. Franceschini, F., Maisano, D., Mastrogiacomo, L., and Pralio, B., "Ultrasound Transducers for Large-Scale Metrology: a Performance Analysis for their use by the MScMS," IEEE Transactions on Instrumentation and Measurement, Vol. 59, No. 1, pp. 110-121, 2010

83. Aebischer, B. and Braunecker, B., "Total Station for Measuring the 3-D Position and Orientation of a Rigid Body," Proc. of the 6th Conference on Optical 3-D Measurement Techniques, Vol. 1, pp. 199-204, 2003

84. Beraldin, J. A., "Integration of Laser Scanning and Close-Range Photogrammetry-the Last Decade and Beyond," Proc. of International Society for Photogrammetry and Remote Sensing, Vol. 7, pp. 972-983, 2004.

85. Orozco, B. V. and Gardunyo, V. G., "Structured Laser Light and 
Coordinate Measuring Systems Integration for 3D Metrology," Proc. of SPIE, 8th International Symposium on Laser Metrology, Vol. 5776, pp. 618-629, 2005.

86. González-Jorge, H., Riveiro, B., Arias, P., and Armesto, J., "Photogrammetry and Laser Scanner Technology Applied to Length Measurements in Car Testing Laboratories," Measurement, Vol. 45, No. 3, pp. 354-363, 2012.

87. Takatsuji, T., Goto, M., Kurosawa, T., Tanimura, Y., and Koseki, Y., "The First Measurement of a Three-Dimensional Coordinate by use of a Laser Tracking Interferometer System based on Trilateration," Measurement Science and Technology, Vol. 9, No. 1, pp. 38-41, 1998.

88. Hughes, E. B., Wilson, A., and Peggs, G. N., "Design of a HighAccuracy CMM based on Multi-Lateration Techniques," Annals of the CIRP, Vol. 49, No. 1, pp. 391-394, 2000.

89. Wendt, K., Franke, M., and Härtig, F., "Mobile Multi-Lateration Measuring System for High Accurate and Traceable 3D Measurements of Large Objects," Proc. of the 10th ISMQC Paper, No. 25, pp. 1-4, 2010.

90. Muelaner, J. E., Cai, B., and Maropoulos, P. G., "Large-Volume Metrology Instrument Selection and Measurability Analysis," Proc. of the Institution of Mechanical Engineers, Part B: Journal of Engineering Manufacture, Vol. 224, No. 6, pp. 853-868, 2010.

91. An eye on global research, http://www.elsevier.com/online-tools/ scopus (Accessed 18 JUL 2014).

92. Bar-Ilan, J., "Citations to the "Introduction to Informetrics" Indexed by WOS, Scopus and Google Scholar," Scientometrics, Vol. 82, No. 3, pp. 495-506, 2010.

93. Labbé, C., "Ike Antkare One of the Great Stars in the Scientific Firmament," International Society for Scientometrics and Informetrics Newsletter, Vol. 6, No. 2, pp. 48-52, 2010.

94. Van Looy, B., Callaert, J., and Debackere, K., "Publication and Patent Behavior of Academic Researchers: Conflicting, Reinforcing or Merely Co-Existing?," Research Policy, Vol. 35, No. 4, pp. 596608, 2006.

95. Breschi, S. and Catalini, C., "Tracing the Links Between Science and Technology: An Exploratory Analysis of Scientists' and Inventors' Networks," Research Policy, Vol. 39, No. 1, pp. 14-26, 2010 .

96. Jun, S. and Lee, S. J., "Emerging Technology Forecasting Using New Patent Information Analysis," International Journal of Software Engineering \& Its Applications, Vol. 6, No. 3, pp. 107-116, 2012.

97. Rogers, E. M., "Diffusion of Innovations," Free Press, 5th Ed., 2013.

98. Cheng, Y. H., Kuan, F. Y., Chuang, S. C., and Ken, Y., "Profitability Decided by Patent Quality? An Empirical Study of the US Semiconductor Industry," Scientometrics, Vol. 82, No. 1, pp. 175183, 2010.
99. Czarnitzki, D., Glänzel, W., and Hussinger, K., "Patent and Publication Activities of German Professors: An Empirical Assessment of their Co-Activity," Research Evaluation, Vol. 16, No. 4, pp. 311-319, 2007.

100. Franceschini, F., Galetto, M., Maisano, D., and Mastrogiacomo, L., "A Review of Localization Algorithms for Distributed Wireless Sensor Networks in manufacturing," International Journal of Computer Integrated Manufacturing, Vol. 22, No. 7, pp. 698-716, 2009.

101. Hoffman, B., Wellenhof, H. L., and Collins, J., "GPS-Theory and Practice," Springer-Wien, 2001.

102. JCGM 200, "The International Vocabulary of Metrology-Basic and General Concepts and Associated Terms (VIM)," International Organization for Standardization, 2008.

103. Mavromihales, M., Mason, J., and Weston, W., "A Case of Reverse Engineering for the Manufacture of Wide Chord Fan Blades (WCFB) used in Rolls Royce Aero Engines," Journal of Materials Processing Technology, Vol. 134, No. 3, pp. 279-286, 2003.

104. Mayoud, M., "Large Scale Metrology for Research and IndustryApplication to Particle Accelerators and Recent Developments," FIG Working Week, 2004.

105. Yang, D. and Cheng, J., "Application of Photogrammetric Technique to Astronomical Telescope Measurement and Control," Proc. of SPIE, Astronomical Structures and Mechanisms Technology, Vol. 5495, pp. 677-684, 2004..

106. Martin, D., "Instrumentation and Calibration at the ESRF," Proc. of the 7th International Workshop on Accelerator Alignment, 2002.

107. Samper, D., Santolaria, J., Brosed, F. J., and Aguilar, J. J., “A StereoVision System to Automate the Manufacture of a Semitrailer Chassis," The International Journal of Advanced Manufacturing Technology, Vol. 67, No. 9-12, pp. 2283-2292, 2013.

108. Sánchez-Lasheras, F., Fernández, R., Cuesta, E., Álvarez, B., Martínez, S., Marcos, M., and Salguero, J., "Study of the Technical Feasibility of Photogrammetry and Coordinated Measuring Arms for the Inspection of Welded Structures," Proc. of AIP Conference Proceedings-American Institute of Physics, Vol. 1431, pp. 311-318, 2012.

109. Luhmann, T. and WENDT, K., "Recommendations for an Acceptance and Verification Test of Optical 3-D Measurement Systems," International Archives of Photogrammetry and Remote Sensing, Vol. 33, No. 5, pp. 493-500, 2000.

110. Muralikrishnan, B., Blackburn, C., and Sawyer, D., "Laser Tracker Testing at NIST using the ASME B89. 4. 19 Standard," The Journal of the CMSC, Vol. 2, No. 2, pp. 11-15, 2007.

111. Huang, Z., Ni, J., and Shih, A. J., "Quantitative Evaluation of Powder Spray Effects on Stereovision Measurements," Measurement Science and Technology, Vol. 19, No. 2, Paper No. 025502, 2008.

112. Ma, G., Zhao, B., and Fan, Y., "Non-Diffracting Beam based Probe 
Technology for Measuring Coordinates of Hidden Parts," Optics and Lasers in Engineering, Vol. 51, No. 5, pp. 585-591, 2013.

113. Pappa, R. S., Lassiter, J. O., and Ross, B. P., "Structural Dynamics Experimental Activities in Ultra-Lightweight and Inflatable Space Structures," NASA Langley Technical Report Server, Document ID: A01-25063, 2001.

114. Shortis, M. R., Robson, S., Pappa, R. S., Jones, T. W., and Goad, W. K., "Characterisation and Tracking of Membrane Surfaces at NASA Langley Research Center," International Archives of Photogrammetry Remote Sensing and Spatial Information Sciences, Vol. 34, No. 5, pp. 90-94, 2002.

115. Sadleir, R. J., Owens, R. A., and Hartmann, P. E., "System for Routine Surface Anthropometry using Reprojection Registration," Measurement Science and Technology, Vol. 14, No. 11, pp. 19121926, 2003.

116. Shortis, M. R., Robson, S., Jones, T. W., and Lunsford, C. B., "Parachute Model Validation using Image Sequences," Proc. of 8th Conference on Optical 3-D Measurement Techniques, pp. 72-79, 2007.

117. Brumbi, D., "Measuring Process and Storage Tank Level with Radar Technology," Proc. of Record of the IEEE 1995 International Radar Conference, pp. 256-260, 1995.

118. Otto, J., "Radar Applications in Level Measurement, Distance Measurement and Nondestructive Material Testing," Proc. of 27th European Microwave Conference, Vol. 2, pp. 1113-1121, 1997.

119. Sen, S., Kenworthy A., "Flow Metering Techniques for Process Measurement and Control", Journal of Flow Engineering and Technology, Vol. 3, No. 6, pp. 73-85, 2014.

120. Qingfeng, W., Qican, Z., and Yuankun, L., "Three-Dimensional Measurement of Object in Water by Tracking Phase Value," Acta Optica Sinica, Vol. 29, No. 6, pp. 1570-1576, 2009.

121. Xie, Z., Li, X., Xin, S., and Xu, S., "Underwater Line StructuredLight Self-Scan Three-Dimension Measuring Technology," Chinese Journal of Lasers, Vol. 37, No. 8, 2010.

122. Schneider, O., "Requirements for Positioning and Navigation in Underground Constructions," Proc. of International Conference on Indoor Positioning and Indoor Navigation (IPIN), pp. 1-4, 2010.

123. Pompili, D., Melodia, T., and Akyildiz, I. F., "Deployment analysis in Underwater Acoustic Wireless Sensor Networks," Proc. of the 1st ACM international workshop on Underwater networks, pp. 48$55,2006$.

124. Estler, W. T., Sawyer, D. S., Borchardt, B. R., and Phillips, S. D., "Large-Scale Metrology Instrument Performance Evaluations at NIST," Journal of the CMSC, Vol. 1, No. 2, pp. 27-32, 2006.

125. Forbes, A. B., "Efficient Algorithms for Structured Self-Calibration Problems," Proc. of 4th Algorithms for Approximation Conference, pp. 146-153, 2002.
126. Franceschini, F., Galetto, M., Maisano, D., and Mastrogiacomo, L., "On-Line Diagnostics in the Mobile Spatial Coordinate Measuring System (MScMS),” Precision Engineering, Vol. 33, No. 4, pp. 408417, 2009.

127. Galetto, M. and Pralio, B., "Optimal Sensor Positioning for Large Scale Metrology Applications," Precision Engineering, Vol. 34, No. 3, pp. 563-577, 2010.

128. Ni, A. J.and Zheng, L. Y., "Optimal Configuration Method for Largescale Measurement Systems Based on Form Error Uncertainty," Acta Metrologica Sinica, Vol. 32, No. 4, pp. 289-295, 2011.

129. Yang, L. H., Wang, Y., Zhu, J. G., and Yang, X. Y., "Distributed Optical Sensor Network with Self-Monitoring Mechanism for Accurate Indoor Location and Coordinate Measurement," Applied Mechanics and Materials, Vol. 190-191, pp. 972-976, 2012.

130. Galetto, M. and Mastrogiacomo, L., "Corrective Algorithms for Measurement Improvement in MScMS-II (Mobile Spatial Coordinate Measurement System)," Precision Engineering, Vol. 37, No. 1, pp. 228-234, 2013.

131. Gholami, M., Cai, N., and Brennan, R., “An Artificial Neural Network Approach to the Problem of Wireless Sensors Network Localization," Robotics and Computer-Integrated Manufacturing, Vol. 29, No. 1, pp. 96-109, 2013.

132. Maropoulos, P. G., "Digital Enterprise Technology-Defining Perspectives and Research Priorities," International Journal of Computer Integrated Manufacturing, Vol. 16, No. 7-8, pp. 467-478, 2003.

133. Maropoulos, P. G., Rogers, B. C., Chapman, P., McKay, K. R., and Bramall, D. G., "A Novel Digital Enterprise Technology Framework for the Distributed Development and Validation of Complex Products," CIRP Annals-Manufacturing Technology, Vol. 52, No. 1, pp. 389-392, 2003.

134. Maropoulos, P. G. and Ceglarek, D., "Design Verification and Validation in Product Lifecycle," CIRP Annals-Manufacturing Technology, Vol. 59, No. 2, pp. 740-759, 2010.

135. Patias, P. and Peipe, J., "Photogrammetry and CAD/CAM in Culture and Industry-an Ever Changing Paradigm," International Archives of Photogrammetry and Remote Sensing, Vol. 33, No. B5, pp. 599603, 2000.

136. VDI Themenradar Automobil, "VDI-Standard: VDI/VDE 2617 Blatt 2.3 Accuracy of Coordinate Measuring Machines - Characteristics and Checking of Characteristics - Acceptance and Reverification Tests for Coordinate Measuring Machines of Large Dimensions," 2005.

137. ASME B89.7.5, "Metrological Traceability of Dimensional Measurements to the SI Unit of Length (An ASME Technical Report)," 2006.

138. ISO 10360-2, "Geometrical Product Specifications (GPS) Acceptance and Reverification Tests for Coordinate Measuring 
Machines (CMM) - Part 2: CMMs used for Measuring Linear Dimensions," 2009.

139. ISO/TS 15530-4, "Geometrical Product Specifications (GPS) Coordinate Measuring Machines (CMM): Technique for Determining the Uncertainty of Measurement - Part 4: Evaluating Task-Specific Measurement Uncertainty using Simulation,” 2008.

140. ISO 15530-3, “Geometrical Product Specifications (GPS) Coordinate Measuring Machines (CMM): Technique for Determining the Uncertainty of Measurement - Part 3: Use of Calibrated Workpieces or Measurement Standards," 2011.

141. VDI/VDE Guideline 2634 Part 1, "Optical 3-D Measuring Systems and Imaging Systems with Point-by-Point Probing,” 2002.

142. ASME B89.4.19, "Performance Evaluation of Laser-Based Spherical Coordinate Measurement Systems,” 2006.

143. Cross, N. R., Dotson, J. R., Flack, D. R., Peggs, G. N., Cox, M. G., et al., "A Large Reference Artefact for CMM Verification," National Physical Laboratory. Great Britain, Centre for Length Metrology, 1998.

144. Brown, N., Veugen, R., van der Beek, G. J., and Hugers, R. F., "Recent Work at NML to Establish Traceability for Survey Electronic Distance Measurement (EDM)," Proc. of SPIE's 48th Annual Meeting Optical Science and Technology, pp. 381-390, 2003.

145. Cox, M. G., Forbes, A. B., Fossati, P. M., Harris, P. M., and Smith, I. M., "Techniques for the Efficient Solution of Large Scale Calibration Problems," National Physical Laboratory, Centre for Mathematics and Scientific Computing, 2003.

146. Canning, J. S. Ziegert, J. C., and Schmitz, T. L., "Uncertainty of Spatial Coordinate Measurements Using Trilateration,” Technical Papers-Society of Manufacturing Engineers, Vol. 33, 2005.

147. Forbes, A. B., "Structured Nonlinear Gauss-Markov Problems," Algorithms for Approximation V, in: Approximation Algorithms for Complex Systems, Georgoulis, E. GH., Iske, A., and Levesley, J., (Ed.), Springer, pp. 167-186, 2007.

148. Forbes, A. B., "Surface Fitting Taking into Account Uncertainty Structure in Coordinate Data," Measurement Science and Technology, Vol. 17, No. 3, pp. 553-558, 2006.

149. Forbes, A. B., "Uncertainty Evaluation Associated with Fitting Geometric Surfaces to Coordinate Data," Metrologia, Vol. 43, No. 4, pp. S282-S290, 2006.

150. JCGM 100, "Evaluation of Measurement Data - Guide to the Expression of Uncertainty in Measurement," 2008.

151. Shin, K.-Y. and Mun, J. H., "A Multi-Camera Calibration Method using a 3-Axis Frame and Wand,” Int. J. Precis. Eng. Manuf., Vol. 13, No. 2, pp. 283-289, 2012.

152. Muelaner, J. E., Wang, Z., Martin, O., Jamshidi, J., and Maropoulos, P., "Estimation of Uncertainty in Three-Dimensional Coordinate Measurement by Comparison with Calibrated Points," Measurement
Science and Technology, Vol. 21, No. 2, Paper No. 025106, 2010.

153. Muelaner, J. E., Wang, Z., Martin, O., Jamshidi, J., and Maropoulos, P. G., "Verification of the Indoor GPS System, by Comparison with Calibrated Coordinates and by Angular Reference," Journal of Intelligent Manufacturing, Vol. 23, No. 6, pp. 2323-2331, 2012.

154. Wang, Q., Zissler, N., and Holden, R., "Evaluate Error Sources and Uncertainty in Large Scale Measurement Systems," Robotics and Computer-Integrated Manufacturing, Vol. 29, No. 1, pp. 1-11, 2013. 